\title{
Firm size and productivity from occupational choices*
}

\author{
Luis Medrano-Adán \\ Centro Universitario de la Defensa (Zaragoza) \\ $\underline{\text { lmedrano@unizar.es }}$ \\ Vicente Salas-Fumás $(+)$ \\ vsalas@unizar.es \\ University of Zaragoza \\ J. Javier Sanchez-Asin \\ jisa@unizar.es \\ University of Zaragoza
}

\begin{abstract}
We model the distributions of firm sizes and of firms' total factor productivity (TFP) as outcomes of a market equilibrium from the occupational decisions of individuals with different entrepreneurial skills, of working as employees, employers or solo entrepreneurs. The model explains empirical regularities such as: i) the positive crosssection correlation between average size of firms and average labor productivity of countries; ii) the positive association between size and TFP of firms in an economy; and iii) the power law distribution of firm sizes. Two parameters of the model, one that measures the organizational size diseconomies, and other related to the dispersion of the distribution of entrepreneurial skills in the population, appear as main determinants of the differences in firm sizes and in productivity, across economies and among firms within an economy. The results of the paper should be of interest for the design and evaluation of firm-size dependent policies.
\end{abstract}

JEL: J24, L25, L26, D24

Key words: Occupational choices, distribution of firm sizes, productivity, power laws distribution, firm-size dependent policies.

(*) Acknowledgements Authors acknowledge financial support from project ECO2013-48496-C4-3-R Spanish Ministry of Economy and Competitiveness, and from the DGA (Aragon Government)- ERDF (European Regional Development Fund) through the CREVALOR research group. The authors thank the valuable comments and suggestions from the two anonymous reviewers and from the Journal Editor on previous versions of the paper. 


\section{INTRODUCTION}

The explanation of why countries differ in per capita income, an indicator of the level of economic development, and the design of policies to close those gaps (convergence), are important topics in Economics. The evidence for a positive association between the average size of firms and the per capita income of countries has motivated national governments and international organizations (the OECD and the IMF) to establish and recommend policies aimed at removing obstacles to the growth of firms and to increase the average size of surviving firms, as a way to increase labor productivity and per capita income. In this respect, the OECD (2014) and the IMF (2015) reports on the Spanish economy both focus on the comparatively small size of Spanish firms as an explanation of the comparatively low productivity of the Spanish economy, seeking policy initiatives to increase the contribution of mid-sized and large firms to the GDP of Spain.

This paper provides a theoretical framework, based on an extension of the original occupational choice models (Lucas, 1978, Jovanovic, 1994), for the study of the determinants of the organization of production, and how this organization determines the average labor productivity and output per capita of the economy. The extension includes, i) the introduction of a third occupational choice, the solo entrepreneur, to the original two choices of employees and employers; and ii) the modeling of the internal organization of jobs and hierarchical levels of firms as part of the production technology. The organization of production in the economy goes beyond the number and size of firms, and includes the contributions of solo entrepreneurs to total employment and output, and the ways in which firms are internally managed and controlled.

The relevance and contribution of the paper is justified, first, by the importance of firmsize-dependent polices and of entrepreneurial enhancement policies of countries around the world, together with the limitations of the occupational choice models used to analyze and evaluate these policies, especially the exclusion of the occupational alternative of solo entrepreneurs. Second, the positive association between average size of firms and per capita income of countries (Bento and Restuccia, 2016) is not fully compatible with the findings of other research on a variety of non-linear relationships between entrepreneurship rates and income per capita of countries; relationships which are sometimes convex (Carree et al., 2002, 2007; Bosma et al., 2008; Gollin, 2008) and 
sometimes concave (van Praag and van Stel, 2013). If each entrepreneur owns and manages one firm, then the proportion of entrepreneurs in all occupied individuals is an inverse measure of the average size of firms and, to be consistent with other empirical results, entrepreneurship rates should be negatively correlated with the per capita income of countries. Our results indicate that the relationship between entrepreneurship rates and per capita income can differ, depending on whether solo entrepreneurs are considered a separate group of the self-employed, or whether all self-employed, with and without employees, are considered as a homogeneous group.

In terms of theory, the paper models the production function of firms as the aggregate output from production in jobs under the management and control of an entrepreneur of given entrepreneurial skills. From the production function and prices of inputs and output, we solve for the market equilibrium from income-maximizing occupational choices of individuals with different skills, working as employees, as solo self-employed, and as employer-managers. The market equilibrium gives the relative size of each occupational group and the distribution of firm sizes, for example in terms of the number of employees hired by each employer-manager and of the average size of all firms in the economy. Since the total number of persons occupied in the economy is given (normalized to one in the model), the total output produced is a measure of labor productivity i.e. output per occupied individual. The first result of the paper is that entrepreneurship rates (the selfemployed, with and without employees), the average size of firms, and output per capita are all endogenous variables jointly determined in the market equilibrium. No causal relationship between entrepreneurship rates and average size of firms, and labor productivity can exist; all the endogenous variables are determined by the values of the exogenous parameters, and it is the differences in these parameters that explain differences in size and productivity.

After the characterization of the equilibrium we conduct comparative static around the market equilibrium solution, i.e. how the relevant endogenous variables of the model - distribution of firm size, entrepreneurship rates, total output produced - respond to changes in the exogenous parameters, organizational size diseconomies and capital intensity of the production technology, cost of capital, dispersion of entrepreneurial skills in the population, etc. We find that equilibrium sizes of firms, total output, sizes of occupational groups, are highly sensible to differences in the values of parameters on 
organizational size diseconomies and dispersion of the distribution of skills. In fact, for those two exogenous parameters, and for practically all the rest, changes in their values imply that the equilibrium average size of firms and labor productivity of the whole economy both change in the same direction. Therefore, we can trace the empirical regularity on size of firms positively correlated with per capita income of countries to cross country differences in the values of the parameters of the model.

Next, we calibrate the parameters of the model with Spanish data on the sizes of occupational groups and provide a validation of the model, comparing the predicted number of firms and occupied individuals across different size classes, with the observed ones. We find that the calibrated model can explain reasonably well the observed distribution of firm size in Spain. Thus, we confirm the validity of occupational choice models to explain and understand why the size distribution of firms differs across countries. Then, we focus on the factors that may condition the current comparatively low productivity and small sizes of Spanish firms, and provide hints for future policy initiatives. In this respect, in the context of the model, greater organizational size diseconomies (from lower delegation of decision power over direct workers by entrepreneurs), and lower dispersion of skills in the working population in Spain, compared to the US, can explain differences in average size of firms and productivity between the two countries. This result can be generalized to explain the observed crosssection correlation between average size of firms and per capita income of countries (Bento and Restuccia, 2016).

Finally, we show that the distribution of TFP of firms in an economy is a monotonic transformation of the distribution of entrepreneurial skills in the occupational group of employers-managers. Since the model also predicts that, in the occupational choice equilibrium, entrepreneurs that are more skilled will manage larger firms, we provide an explanation of the empirically observed positive correlation between size and TFP of firms (Idson and Oi, 1999; Hsieh and Klenov, 2009, 2014; Syverson, 2011). In addition, we find that the distribution of firm sizes is simply a power transformation of the truncated distribution of entrepreneurial skills, with lower bound in the number of employees equal to that employed by the entrepreneur with skills that make her indifferent between working as solo self-employed or as employer-manager. This result is important in clarifying when and why the values of the variable size of firms follow a 
power law distribution (Axtell, 2001; Gabaix, 2016), as well as in clarifying the origin of the "missing middle" (Hsieh and Olken, 2014), and whether or not it is relevant to the design of firm-size dependent policies.

The rest of the paper is organized as follows. Section 2 contains a review of the related literature and highlights the contribution of the paper to the literature on occupational choice. Section 3 presents the basic elements of the theoretical model, particularly the production function of solo entrepreneurs and employers, together with the characterization of the market equilibrium with three occupational choices. Section 4 shows the results of the calibration of the parameters of the model, the comparison of predicted and observed distribution of firm sizes in Spain, and some comparative static results. Section 5 presents additional extensions of the properties of the market equilibrium to explain other regularities around the relationship between size of firms and productivity of the economy. The conclusion section discusses our main results in the context of the literature.

\section{RELATED LITERATURE AND EXTENSIONS OF THE OCCUPATIONAL CHOICE MODELS}

Lucas (1978) was the first to establish a relationship between the size of firms and the per capita income of economies, from occupational choice models: in economies where the elasticity of substitution between labor and capital in production is lower than one, greater capital deepening will increase both the average size of firms and average labor productivity. Therefore, in a cross/section of countries with different levels of capital, a positive association is expected between per capita income and the average size of firms. Lucas argues that, since it can reasonably be expected that the US economy will increase capital intensity over time, the relative share of output from large firms and the average labor productivity will both increase over time too.

However, the empirical evidence indicates that the relative importance of small and large firms does not show a linear trend over time, and that countries with similar economic development continue to have permanent differences in entrepreneurship rates. This means that the stock of capital is not the only driver of the association between size of firms and productivity. Furthermore, Lucas (1978) and other early occupational choice 
models ignore the solo self-employed as a third occupational choice (Salas-Fumás et al., 2014), and also overlook the importance of how firms organize internally - for example, their span of control and hierarchical levels (Penrose, 1959; Calvo and Wellisz, 1980; Rosen, 1982), as determinants of the limits to the growth of the firms. This paper extends Lucas' model to include the occupational choice of solo entrepreneurs and explicitly model the organization of production and control within firms.

Following the literature, the quality of strategic decisions is part of the total factor productivity component of the production technology (better or worse decisions affect the productivity of all resource inputs). However, the supervision input is allocated across individuals at lower levels of the hierarchy, and its contribution to produced output is affected by decreasing returns to scale. This means, in the context of the model, that a production function with constant technological returns to scale becomes a production function with decreasing returns, due to the internal costs of growth resulting from agency costs and loss of control in hierarchical organizations (Penrose, 1959; Calvo and Wellisz, 1980). The fact that the limits to the size and growth of firms have to do with management costs in hierarchical organization structures, explains why the paper refers to decreasing returns to scale in production as organizational size diseconomies.

The number of solo self-employed individuals is relatively high in many economies (in Spain, they represent around $12.5 \%$ of all occupied persons in the market economy - with the exclusion of agriculture - twice the proportion of employers) and the size distribution of firms will be incomplete if solo self-employment is omitted from the analysis. Moreover, the negative association between per capita income of countries and entrepreneurship-self-employment rates, observed when all self-employed are considered as a homogeneous group (Blanchflower, 2004; Gollin, 2008), changes when selfemployment is split into solo entrepreneurs and employers, so that it applies only to the rate of solo entrepreneurs (Salas-Fumás et al., 2014). The explanation of the distribution of firm sizes separating firms with and without employees, contributes to a better understanding of why some entrepreneurs contribute more than others do to output and the productivity of the whole economy (Shane, 2009; Parker, 2009).

Another line of research empirically attributes national differences in firm sizes to differences in the economic and institutional environment: taxes, employment laws, 
regulation of financial markets, and the size of the public sector (Blau, 1987; Davis and Henrekson, 1999; Henrekson and Johansson, 1999). The recommendations of public policies to increase the size of firms in Spain as a way to increase productivity, by the OECD (2014) and the IMF (2015), assume that some size-dependent economic policies (for example that firms with 50 employees or higher must create workers councils) affect the size distribution of firms. Other papers follow research into distortions in the allocation of resources from firm-size dependent public policies (Restuccia and Rogerson, 2008; Guner et al., 2008). They include, Onji (2009) for Japan, Schivardi and Torrini (2008) for Italy, Garicano et al. (2016) for France, and Branstetter et al. (2014) for Portugal. This paper shows that cross-country differences in the average size of firms and in labor productivity can occur, even among free-market economies, when economies differ in the distribution of entrepreneurial skills, production technology, and management of firms.

\section{THE PRODUCTION TECHNOLOGY AND MARKET EQUILIBRIUM}

This section describes the joint production involving direct labor, capital services, and inputs from entrepreneurs, together with the market equilibrium from occupational choice of individuals who differ in their entrepreneurial skills ${ }^{1}$.

\subsection{Production function}

The basic production unit is a job position. Jobs can operate independently, occupied by a solo entrepreneur, or they can be grouped in firms under the hierarchical direction of an entrepreneur-manager. In the economy, there is only one final good with selling price normalized to one by assumption. The production of the final good requires three inputs supplied by the employees, the capital, and the entrepreneur.

As in Lucas (1978) and Rosen (1982), inputs from the entrepreneur enter into the production function together with capital and direct labor. Obtaining the final output

\footnotetext{
${ }^{1}$ The model assumes complete and symmetric information. The occupation choice between entrepreneurs and employees has also been explained by the different degree of risk aversion of individuals and uncertain pay-offs from entrepreneurship (Khilstrom and Laffont, 1979). When individuals learn their entrepreneurial skills from experience, then the occupational choice equilibrium is the convergence point of a dynamic process (Jovanovic, 1982; Hopenhayn, 1992).
} 
involves a three-stage process: first, we define an intermediate output at the job level by simply combining labor and capital inputs; next, we combine the intermediate output with the input of the entrepreneur-manager to obtain the level of final output of one job position; and finally, we solve for the output-maximizing number of jobs, to be aggregated under the direction of an entrepreneur of given skills.

The production technology in job $j$ gives the level of intermediate output $y_{j}$ as a function of quantities of labor and capital inputs, $l_{j}$ and $k_{j}$ respectively. The corresponding production function, the same for all jobs, is a constant elasticity of substitution, CES, function,

$$
y_{j}=\left[\mu l_{j}^{-\rho}+(1-\mu) k_{j}^{-\rho}\right]^{-\frac{1}{\rho}}
$$

The parameter $0<\mu<1$ determines the relative labor intensity of the production technology, and $\rho$ determines the value of the constant elasticity of substitution, $\sigma=1 /(1+\rho)$ with $-1<\rho$. For $\rho=0$, the CES converges to the Cobb Douglas $(\sigma=1)$ production function.

The intermediate output, $y_{j}$, is combined with the inputs from the entrepreneur of given skills to be converted into final output. As in Rosen (1982), the entrepreneur contributes in two ways, making the strategic decisions on what to produce and how, and assuring the proper implementation of decisions. The input from the strategic decision is shared by all jobs in the organization, in the sense that the quality of the decision will affect the productivity of all the resources under the direction of the entrepreneur. The implementation of the strategic decision will require the supervision and/or problemsolving support of the entrepreneur, on a job-by-job basis. We define by $e$, positive, the level of skills of the entrepreneur, directly related to the quality of the decision, and by $e t_{j}$ the skills-weighted working time of the entrepreneur allocated to job position $j$. The final output produced in job $j, Y_{j}$, with the combination of the intermediate output and the entrepreneurs' inputs, is given by:

$$
Y_{j}=\theta g(e)\left(e t_{j}\right)^{\beta} y_{j}^{1-\beta}=\theta g(e)\left(e t_{j}\right)^{\beta}\left[\mu l_{j}^{-\rho}+(1-\mu) k_{j}^{-\rho}\right]^{\frac{-(1-\beta)}{\rho}}
$$


The term $\theta$ is a positive parameter that captures the level of productivity of the economy, common to all jobs and production units. The function $g(e)$, increasing in $e$, captures the contribution to output from the quality of the strategic decisions of the entrepreneur. Function (2) is linear homogeneous in the management input, etj, and the intermediate output $y_{j}$. The parameter $0<\beta<1$ captures the relative intensity of the skills-weighted time of the entrepreneur in the production of job $j$. We assume that the parameter $\beta$ captures characteristics of the internal organization and management of firms. For example, higher (lower) centralization and involvement of the entrepreneur in the implementation stage will be associated with higher (lower) values of $\beta$. There is empirical evidence that delegation of decision power is higher in firms of countries with higher levels of generalized trust (Gur and Bjornskov, 2016), which is interpreted as evidence that trust reduces agency and control costs in hierarchical organizations. Therefore, the value of parameter $\beta$ is expected to vary inversely with the levels of generalized trust in the economy ${ }^{2}$.

The labor input per job $l_{j}$ is fixed. The entrepreneur of skills $e$ is endowed with $\mathrm{K}$ units of capital and $\mathrm{T}$ units of working time and decides how to allocate the two inputs in the $M \geq 2$ jobs. All the jobs under the direction of an entrepreneur of skills $e$ will benefit equally from the quality of the strategic decisions, so the term $g(e)$ will be an input in the $M$ jobs. The entrepreneur allocates working time and capital endowment so that total output produced is maximized:

$$
\begin{aligned}
& \operatorname{Max}_{t_{j}, k_{j}} \sum_{j}^{M} Y_{j}=\sum_{j}^{M} \theta g(e)\left(e t_{j}\right)^{\beta}\left[\mu l_{j}^{-\rho}+(1-\mu) k_{j}^{-\rho}\right]^{\frac{-(1-\beta)}{\rho}} \\
& \text { subject to } \sum_{j}^{M} t_{j} \leq T, \quad \sum_{j}^{M} k_{j} \leq K
\end{aligned}
$$

From the linear homogeneous property of the job production functions of the intermediate output, equation (1), and final output, equation (2), the optimal solution implies:

\footnotetext{
${ }^{2}$ In Garicano (2000) and Garicano and Rossi-Hansberg (2006) entrepreneur-managers contribute to production using their specialized knowledge to help employees solve complex problems. In the market equilibrium, there is an optimal matching of employees and managers, while in Rosen (1982) all employees can be perfectly exchanged among employers.
} 


$$
\begin{aligned}
& \frac{k_{j}}{l_{j}}=\frac{\sum_{j}^{M} k_{j}}{\sum_{j}^{M} l_{j}}=\frac{K}{L}=d_{1}(\text { Constant }) \\
& \frac{t_{j}}{l_{j}}=\frac{\sum_{j}^{M} t_{j}}{\sum_{j}^{M} l_{j}}=\frac{T}{L}=d_{2} \text { (Constant) }
\end{aligned}
$$

If the working time of employees and entrepreneur is normalized to 1 , then $T=1$ and the input from employees, $L$, is equal to the number of employees (each contributing with one unit of input). Substituting (3) and (4) in the production function and with $T=1$, the total output produced by an entrepreneur of skills $e$ is given by:

$$
Y=\theta g(e) e^{\beta}\left[\mu L^{-\rho}+(1-\mu) K^{-\rho}\right]^{\frac{-(1-\beta)}{\rho}}
$$

For values of $1>\beta>0$, the production function at the firm level has decreasing returns to scale (recall that the skills of the entrepreneur $e$ are fixed). The diseconomies in the quantities of number of employees and capital inputs employed in production increase with the value of the parameter $\beta$, that in turn depends ultimately on how firms are organized and managed internally. To differentiate these scale diseconomies from pure technological ones (the technology at the job level has constant returns to scale to labor and capital), we will interpret higher values of $\beta$ as an indicator of higher organizational size diseconomies.

\subsection{Solo entrepreneurs}

The solo entrepreneurs occupy jobs where production is the result of combining their own skills together with purchased capital input services and fixed working time. The solo entrepreneur makes the strategic decisions and contributes to production at the job level with a fixed quantity of labor input $l_{j}$ that will also be normalized to one. Since the solo entrepreneurs do not hire employees, then no hierarchical structure is needed to control production $(\beta=0)$. From (1), the production function of the solo entrepreneur with skills $e$ is given by: 


$$
Y_{j s}=\theta h(e)\left[\mu l_{j}^{-\rho}+(1-\mu) k_{j}^{-\rho}\right]^{-\frac{1}{\rho}}
$$

where $Y_{j s}$ is the output and $h(e)$, positive and increasing function of skills, is the contribution to output of the quality of the entrepreneurial decision, similar to $g(e)$ in the production function of entrepreneurs who hire employees.

\subsection{Related literature}

In Lucas (1978), each direct employee supplies one unit of working time, $l_{j}=1$. Therefore, $L$ is also the number of employees under the direction of the entrepreneur of skills $e$. Lucas ignores the internal organization of work within the firm (i.e. makes $\beta=$ 0 ). The condition of decreasing returns to scale needed to obtain a finite solution in the output of firms is imposed exogenously and the production function is written as $Y=\theta g(e)[F(L ; K)]^{\tau}$, where $0<\tau<1$ is the parameter that determines, inversely, the degree of decreasing returns to scale.

Rosen (1982) considers that individuals are endowed with a general skill $q$ that is used either in entrepreneurial or operational tasks. If one unit of general skill is equivalent to one unit of operational skill, and the working time is normalized to one, then the labor input supplied by $L$ employees, each endowed with $q_{j}$ units of general skill, is $Q=\sum_{j}^{L} q_{j}$. Then, the sum of operational skills, $Q$, would replace the number of employees, $L$, in the production function (6), although Rosen does not include capital as a productive input. Throughout this paper, we assume that all individuals are endowed with one unit of operational skill and they differ only in entrepreneurial skills.

In Gollin (2008), the production technologies of both entrepreneur-managers and solo entrepreneurs have decreasing returns to scale and the entrepreneurial skills enter into the production function as in Lucas (1978), i.e. the internal organization of firms is not part of the model. In the equilibrium, the solo entrepreneur works part-time as solo selfemployed and part-time as employee. However, in the empirical analysis, all selfemployed are treated as a homogeneous group. In Guner et al. (2008), there are only 
entrepreneur-managers and employees, and the production function is of the Cobb Douglas type. They assume that the production function is linear homogeneous in skills $e$ and the output from the combination of labor and capital; the function resembles equation (6) but with elasticity of substitution equal to one and $g(e)=1$.

In sum, although there are similarities between our production function at the firm level and other production functions in the literature inspired by Lucas (1978), a distinct feature of this paper is that diseconomies of scale in quantities of capital and direct labor inputs are attributed to the way firms are internally organized and managed and, more specifically, to the time entrepreneurs employ in implementing the strategic decisions.

\subsection{Individuals, skills, and pay-offs from occupational decisions}

The economy has a fixed total number of individuals, normalized to one with individuals on the continuum of points from zero to one, endowed with one unit of operational skill and a different level of entrepreneurial skill $e$. The distribution of entrepreneurial skills in the population is assumed to follow a Pareto distribution, whit cumulative distribution function $\Gamma(e)$,

$$
\Gamma(e)=1-\left(\frac{b}{e}\right)^{a} \quad \text { for } e \geq b \geq 0
$$

where $b$ is the lower bound of the distribution and $a$ is a parameter that determines the coefficient of variation (inversely), $C V=[a(a-2)]^{-1 / 2}$. Given $b$, the lower the value of $a$, the heavier the upper tail of the distribution and the higher the mean, the variance and the coefficient of variation. The Pareto distribution has the properties that the larger fraction of individuals concentrates at the lower end of the distribution, and the probability density function is strictly decreasing and convex in $e$. But maybe its most distinctive feature is that its survival and density probability functions are isoelastic, with elasticities equal to $-a$ and $-(1+a)$ respectively. 
Lucas assumed a Pareto distribution of skills in his original paper. The Pareto distribution imposes asymmetry on the distribution of skills but, as will be evident later, the asymmetry of the distributions of the relevant size of the firm variables, number of employees, output, capital stock, is determined by other factors in addition to the asymmetry of the distribution of skills.

Individuals choose an occupation, to work as employees, to work as solo entrepreneurs, or to work as entrepreneur-managers, i.e. self-employed that hire employees. The choice responds to the criteria of maximizing income. We assume that there is perfect supply of capital services at a market cost of capital ${ }^{3}, c$. The supply of employees is equal to the total population minus the number of individuals who choose to be entrepreneurs. The demand for employees comes from the entrepreneur-managers. A market-determined salary for employees, $w$, will balance demand and supply. To save in notation, throughout the paper we assume $h(e)=g(e)=e$.

An employee earns the market salary $w$, independently of his/her level of entrepreneurial skills. The income of the entrepreneur is the profit from production and sales, which depends on the entrepreneurial skills. The net income of the solo entrepreneur with skills $e, R(e)$, is given by (the direct labor of the self-employed is 1 , the same as of any employee):

$$
R(e)=\operatorname{Max}_{K} \theta e\left[\mu+(1-\mu) K^{-\rho}\right]^{\frac{-1}{\rho}}-c K
$$

The optimal solution to this problem gives:

$$
\begin{gathered}
K^{*}(w, c, e)=\left(1-\frac{1}{\mu}+\frac{1}{\mu}\left(\frac{\theta(1-\mu)}{c} e\right)^{\frac{\rho}{1+\rho}}\right)^{\frac{1}{\rho}} \\
Y_{s}^{*}(e)=\left(\frac{(\theta e)^{\rho}}{1-\mu}\right)^{\frac{1}{1+\rho}}\left(1-\frac{1}{\mu}+\frac{1}{\mu}\left(\frac{\theta(1-\mu)}{c} e\right)^{\frac{\rho}{1+\rho}}\right)^{\frac{1}{\rho}}
\end{gathered}
$$

\footnotetext{
${ }^{3}$ In Lucas (1978) the cost of capital $c$ is equal to the shadow price of the constraint on total capital available. Rosen (1982) does not include capital as a production input. Other papers, Gollin (2008) and Guner et al. (2008), solve endogenously for the discount factor in a market equilibrium where consumers make saving decisions and producers make investment decision. We assume that financial markets optimally separate consumption from production decisions, and the users' cost of capital is the slope of the separating line.
} 


$$
R(e)=\left(\frac{1}{\mu}\right)^{\frac{1}{\rho}}\left((\theta e)^{\frac{\rho}{1+\rho}}-(1-\mu)^{\frac{1}{1+\rho}} c^{\frac{\rho}{1+\rho}}\right)^{\frac{1}{\rho}}
$$

Similarly, the income-profit of the entrepreneur-manager with skill $e$ is equal to:

$$
\Pi(e)=\operatorname{Max}_{K, L} \theta e e^{\beta}\left[\mu L^{-\rho}+(1-\mu) K^{-\rho}\right]^{\frac{-1}{\rho}}-w L-c K
$$

From the first order conditions, the demands for labor and capital by the entrepreneurmanager of skill $e$ are,

$$
\begin{gathered}
L^{*}(e, w)=\theta^{\frac{1}{\beta}}(1-\beta)^{\frac{1}{\beta}}\left(\frac{\mu}{w}\right)^{\frac{1}{1+\rho}}\left((1-\mu)^{\frac{1}{1+\rho}} c^{\frac{\rho}{1+\rho}}+\mu^{\frac{1}{1+\rho}} w^{\frac{\rho}{1+\rho}}\right)^{\frac{-\rho-1+\beta}{\rho \beta}} e^{\frac{\beta+\tau}{\beta}} \\
K^{*}(e, w)=\left(\frac{(1-\mu)}{\mu} \frac{w}{c}\right)^{\frac{1}{1+\rho}} L^{*}(e, w)
\end{gathered}
$$

The optimal output and profits are:

$$
\begin{gathered}
Y(e)=\theta^{\frac{1}{\beta}}(1-\beta)^{\frac{1-\beta}{\beta}}\left((1-\mu)^{\frac{1}{1+\rho}} c^{\frac{\rho}{1+\rho}}+\mu^{\frac{1}{1+\rho}} w^{\frac{\rho}{1+\rho}}\right)^{\frac{-(1+\rho)(1-\beta)}{\rho \beta}} e^{\frac{\beta+1}{\beta}} \\
\Pi^{*}(e)=\beta Y^{*}(e)
\end{gathered}
$$

\subsection{Market equilibrium}

In a decentralized market economy, individuals make occupational choices, comparing the pay-offs of the occupation alternatives at given market prices until the equilibrium is reached. Since the price of capital services is given, the market price to solve for in the equilibrium is the employees' salary, $w$. The equilibrium must satisfy two conditions: first, there is a salary for which the supply of employees is equal to the demand by employers; and, second, no individual will want to change occupation. The second condition will be satisfied if an individual with given entrepreneurial skills earns higher income in the occupation that is part of the equilibrium than in any other. 
The market equilibrium allocates individuals to the three occupational groups. The market salary of employees is independent of the level of entrepreneurial skills of the employee, while incomes of solo entrepreneurs (9) and of entrepreneur-managers (11) are both increasing and convex functions of skills. From the properties of the salary and profit functions, in the market equilibrium, the profits of solo entrepreneurs and of entrepreneurmanagers will both intersect the salary function from below. Moreover, in the equilibrium with non-empty groups of employees, solo entrepreneurs, and entrepreneur-managers, the differences in convexity with skills of profits of the two types of entrepreneur imply that there will be a level of skill where the profit function of entrepreneur-managers will intersect from below the profit function of the solo self-employed (see figure 1). From these properties of the income functions, and with the condition that the supply of employees equals demand, the market equilibrium is determined by the values of skills $e_{1}<e_{2}$ that satisfy the conditions:

$$
\begin{gathered}
R\left(e_{1}\right)=w^{*} \\
\Pi\left(e_{2}\right)=R\left(e_{2}\right) \\
\int_{b}^{e_{1}} d \Gamma(e)=\int_{e_{2}}^{+\infty} L^{*}\left(e, w^{*}\right) d \Gamma(e)
\end{gathered}
$$

where $w^{*}$ is the salary for which the supply of employees equals the demand. Individuals with entrepreneurial skills in the interval $b \leq e \leq e_{1}$ work as employees; those with skills in the interval $e_{1} \leq e \leq e_{2}$ work as solo entrepreneurs; and those with skills $e \geq e_{2}$ will be employers-managers.

The equations (12) to (14), after substituting $R(e), \Pi(e)$, and $L^{*}(e, w)$ given by (9), (11) and (10) respectively, appear written in detail in Appendix A. A necessary condition for a finite demand for employees is that $\beta(a-1)>1$. If this condition holds, then we can prove that the equilibrium exists and is unique ${ }^{4}$. Figure 1 shows the market

\footnotetext{
${ }^{4}$ The proof is not reported to save space but is available from the authors on request.
} 
equilibrium solution for values of the parameters of the model calibrated in the following section with Spanish data.

\section{(FIGURE 1)}

The figure on the left shows the representation of the salary of employees, net income of the solo entrepreneurs, and profits of entrepreneurs-managers, for the equilibrium salary $w^{*}$. The intersections of these functions determine the equilibrium relative numbers of individuals in each occupational group: individuals with lower entrepreneurial skills $(e<$ $e_{1}$ with $e_{1}=4.53$, for the selected parameter values) work as employees; those with intermediate skills $\left(e_{1} \leq e<e_{2}\right.$ with $\left.e_{2}=5.48\right)$ are solo entrepreneurs, and those with higher entrepreneurial skills $\left(e \geq e_{2}\right)$ are entrepreneurs-managers. The figure on the right shows the demand and supply of employees as a function of the salary. The intersection determines the values $\left(L^{*}, w^{*}\right)$, where $w^{*}=5.52$ is the market-clearing salary and $L^{*}=$ 0.79 is the equilibrium proportion of individuals working as employees (also equal to the aggregate labor demand of the employers).

More formally, the results from the market equilibrium are summarized in Result 1 as follows:

Result 1. In the market equilibrium from equations (12), (13) and (14), with functions $R(e), \Pi(e)$, and $L^{*}(e)$ given by equations (9), (11) and (10) and a Pareto distribution of entrepreneurial skills, the following holds:

a) There will be $\Gamma\left(e_{1}\right)=1-\left(\frac{b}{e_{1}}\right)^{a}$ employees, $\Gamma\left(e_{1}\right)-\Gamma\left(e_{2}\right)=\left(\frac{b}{e_{1}}\right)^{a}-\left(\frac{b}{e_{2}}\right)^{a}$ solo entrepreneurs, and $1-\Gamma\left(e_{2}\right)=\left(b / e_{2}\right)^{a}$ entrepreneurs-managers. The total output, $T Y_{T}{ }^{*}$, is equal to the sum of output produced by the firms with employees, $T Y^{*}$, and the output produced by the solo entrepreneurs, $T Y_{s}^{*}$ : $T Y_{T}^{*}=T Y^{*}+T Y_{s}^{*}=\int_{e_{2}}^{\infty} Y^{*}\left(e ; w^{*}\right) d \Gamma(e)+\int_{e_{1}}^{e_{2}} Y_{s}^{*}(e) d \Gamma(e)$, where $Y^{*}\left(e, w^{*}\right)$ is given by equation (10), $Y_{s}^{*}(e)$ by equation (11), and $w^{*}$ is the equilibrium salary. 
b) The distribution of firm size, with size measured by number of employees, i.e. the proportion of firms with employees less than or equal to $L$, for $L \geq L_{\min }=L^{*}\left(e_{2}, w^{*}\right)$, is given by

$$
\Gamma_{\% \text { firms }}(L)=1-\left(\frac{L_{\min }}{L}\right)^{\frac{a \beta}{1+\beta}}
$$

where

$$
L_{\min }=L^{*}\left(e_{2}, w^{*}\right)=\theta^{\frac{1}{\beta}}(1-\beta)^{\frac{1}{\beta}}\left(\frac{\mu}{w^{*}}\right)^{\frac{1}{1+\rho}}\left((1-\mu)^{\frac{1}{1+\rho}} c^{\frac{\rho}{1+\rho}}+\mu^{\frac{1}{1+\rho}} w^{\frac{\rho}{1+\rho}}\right)^{\frac{-\rho-1+\beta}{\rho \beta}} e_{2}^{\frac{\beta+1}{\beta}} .
$$

c) The proportion of employees in firms with size less than or equal to $L$ employees, for $L \geq L_{\min }=L^{*}\left(e_{2}, w^{*}\right)$ is given by

$$
\Gamma_{\% \text { emplyoees }}(L)=\int_{e_{2}}^{L^{-1}(L)} L^{*}(e) d \Gamma(e)=1-\left(\frac{L_{\min }}{L}\right)^{\frac{\beta(a-1)-1}{1+\beta}}
$$

d) The proportion of firms, $\Gamma_{\% \text { firms }}(L)$, as a function of the proportion of employees in these firms, $\Gamma_{\% \text { emplyoees }}(L)$, is given by

$$
\Gamma_{\% \text { firms }}(L)=1-\left[1-\Gamma_{\% \text { emplyoees }}(L)\right]^{\frac{a \beta}{\beta(a-1)-1}}
$$

The average size, number of employees, of firms with employees, $A S F$, is

$$
A S F^{*}=\frac{\int_{e_{2}}^{\infty} L^{*}\left(e, w^{*}\right) d \Gamma(e)}{\left(b / e_{2}\right)^{a}}=\frac{1-\left(b / e_{1}\right)^{a}}{\left(b / e_{2}\right)^{a}}
$$

e) The distribution of TFP of firms with employees is a Pareto distribution with parameters $\left(\theta e_{2}, a\right)$, so that, its cumulative distribution function is given by

$$
H(x)=1-\left(\frac{\theta e_{2}}{x}\right)^{a} \quad \text { for } \quad x \geq \theta e_{2}
$$

Explanation: distribution of firm size 
Result 1.a) describes the mapping between the distribution of skills and the relative size of each occupational group (employees, solo entrepreneurs, and employers) in the market equilibrium. It also gives the total output produced in the market equilibrium, equal to the sum of the output of firms with employees and the output of solo entrepreneurs. Since the number of occupied individuals is normalized to one, the total output produced is also the output produced per occupied individual, i.e., the average labor productivity of the economy in the market equilibrium.

Results 1.b) and 1.c) imply that, in the equilibrium, the distribution of firm size and the distribution of employees in firms of different sizes, are Pareto distributions. The minimum firm size, number of employees, $L_{\min }$, is that of the firm managed by the lessskilled employer in both cases, while the power parameters are, respectively, $\frac{a \beta}{1+\beta}$ and $\frac{\beta(a-1)-1}{1+\beta}=\frac{a \beta}{1+\beta}-1$. Since the value of the power parameter of the distribution of firm size, $\frac{a \beta}{1+\beta}$, is greater than the value of the power parameter of the distribution of employees across firm sizes, $\frac{\beta(a-1)-1}{1+\beta}$, the size distribution of firms will show a greater concentration across firm sizes than the distribution of employees.

In fact, the cumulative distribution function of employees in firms of different sizes, (Result 1.d) is an increasing and concave function of the cumulative distribution function of firm sizes, and the curvature and the slope of this function depends only on parameter $a$, related to the dispersion of skills in the population, and on parameter $\beta$, the measure of organizational size diseconomies. The two parameters determine the slope of the distribution of firm size in the economy, so that higher (lower) values of this slope imply more (less) firms concentrated in the lower size classes and, therefore, a smaller (larger) average size of firms with employees, for a given minimum size $L_{\min }$. The average size in number of employees of firms with employees is given by equation (17).

The distribution of firm sizes for firms that hire employees along the dimension of number of employees, $L$, is defined from the lower bound of number of employees, $L$ min that 
corresponds to the size of the firm managed by an entrepreneur with skills $e_{2}$. Then, there is a one-to-one correspondence between the number of employees of the firm, $L \geq L_{\mathrm{min}}$, and the skill of the entrepreneur who manages the firm, $e \geq e_{2}$. In fact, from equation (10), the distribution of firm sizes (15) is the power transformation $L^{*}\left(e, w^{*}\right)$ of the lefttruncated distribution of skills, defined for skill (size) values $e \geq e_{2}\left(L \geq L_{\mathrm{min}}\right)$.

\section{Explanation: distribution of TFP}

From equation (6), the production function of the firm managed by an entrepreneur with skills $e$ is given by $Y=\theta g(e)(e T)^{\beta}\left[\mu L^{-\rho}+(1-\mu) K^{-\rho}\right]^{\frac{-(1-\beta)}{\rho}}$. There are three inputs that directly contribute to the total output produced: skill-weighted working time of the entrepreneur, $e T$, with $T=1$ by assumption, direct labor, $L$, and capital, $K$. The TFP of the firm is equal to the ratio between output $\mathrm{Y}$ and the contribution to this output from the three direct labor inputs:

$$
T F P=\frac{Y}{e^{\beta}\left[\mu L^{-\rho}+(1-\mu) K^{-\rho}\right]^{\frac{-(1-\beta)}{\rho}}}=\theta g(e)
$$

The parameter $\theta$ is common to all firms and represents the general stage of development of the economy. The function $g(e)$, increasing with entrepreneurial skills $e$, is the contribution to output attributed to the quality of the decisions of the entrepreneur that leverages the productivity of direct inputs in all job positions.

Results 1.e) means that the distribution of TFP of firms is an increasing monotone transformation, $\theta g(e)$, of the left-truncated distribution of entrepreneurial skills in the population, truncated at $e_{2}$.

Since $\theta$ is the same for all firms in the economy, differences in TFP across firms will only depend on $g(e)$. Throughout the paper, we assume that $\theta=1$ and $g(e)=e$; so, under this assumption, the distribution of TFP of production units in the economy will coincide with the distribution of skills of their respective entrepreneurs, as represented by equation 
(18) with $\theta=1$. In the range of skills $e_{1} \leq e<e_{2}$ the distribution of skills and TFP will be that of the solo entrepreneurs, while for skills $e_{2} \leq e$ the distribution of TFP of firms will be the distribution of skills of their entrepreneurs-managers ${ }^{5}$.

\section{CALIBRATION OF THE PARAMETERS OF THE MODEL AND COMPARATIVE STATIC ANALYSIS}

The market equilibrium from occupational choices does not have a closed solution. In this section, we calibrate the values of the parameters with data from sizes of occupational groups in Spain, and use the values to validate the model, comparing predicted distributions with the observed ones, and to explain differences in the average size of firms and average productivity of Spain relative to other countries, particularly the US.

\subsection{Calibration of the parameters}

The list of parameters for the calibration includes: the general TFP, $\theta$; the user cost of capital, $c$; the elasticity of substitution between labor and capital in the production function, $\sigma=1 /(1+\rho)$; the relative labor intensity of the production technology, $\mu$; the organizational size diseconomies, $\beta$; and the parameters $a$ and $b$ of the Pareto distribution of skills.

The value of $\theta$ is normalized to 1 . The user cost of capital $c$ is set to $12 \%$ ( $4 \%$ of the financial cost of capital and $8 \%$ of the depreciation rate). The $4 \%$ is the average real cost of debt for Spanish non-financial corporations in the last ten years, and the depreciation rate of $8 \%$ is the ten-year average of the ratio between amortization allowances and gross tangible assets (Banco de España, 2014). The parameters of relative intensity of labor input in production, $\mu$, and of the elasticity of substitution between labor and capital $\sigma$, are set to $\mu=0.75$ and $\sigma=2 / 3(\rho=0.5)$, similar to those calibrated for other developed countries (Guner et al., 2008; Gollin, 2008).

\footnotetext{
${ }^{5}$ In general, if $\theta \neq 1$ and $g(e) \neq e$, the distribution of TFP will be an increasing non-linear transformation of the left-truncated distribution of entrepreneurial skills.
} 
We are left with three parameters $\beta, a$, and $b$. In the calibration of these parameters, we use real data on the sizes of occupational groups, and on the proportion of individuals occupied in large firms in Spain. Thus, we avoid using actual data on the distribution of firm sizes. The absolute and relative sizes of occupational groups in Spain are reported in Table 1, for years 2005 (expansion period) and 2013 (contraction period). The numbers of total occupied in the table include only those working in the non-agricultural market sector of the economy (therefore, all public employees and those occupied in agriculture are excluded). The column of "employees" excludes those occupied in general management positions that official statistics include as salaried employers, but that we report in Table 1 in the separate column of "managers". We do so because general managers perform entrepreneurial functions similar to those of employers and business owners, different from those performed by the direct employees.

\section{(TABLE 1)}

According to the values in Table 1, the proportions of employees, employers plus managers, and of solo self-employed over all occupied individuals in the market economy in Spain are set equal to $0.79,0.085$, and 0.125 , respectively. If there is one entrepreneur per production unit, then these proportions imply that, of the total number of units, with and without employees, almost $60 \%(0.125 / 0.21)$ do not have employees.

Since the three proportions of individuals in occupation groups add to one, in the calibration we can only use two of them. The third observed data value needed to calibrate the three remaining parameters is taken from OECD (2014) data on the proportion of occupied individuals in firms with 250 or more employees. For Spain, this proportion is $24 \%$ of all those occupied in firms with employees in 2009 , the first year available, and $26 \%$ in 2013 , the last year available. Therefore, the value of 0.25 for the proportion of individuals occupied in large firms is a reasonable reference for completing the calibration.

According to Result 1.a) above, the proportion of employees in the equilibrium is given by $\Gamma\left(e_{1}\right)=1-\left(b / e_{1}\right)^{a}$, and the proportion of employer-managers by $1-\Gamma\left(e_{2}\right)=\left(b / e_{2}\right)^{a}$. The proportion of individuals occupied in firms with 250 or more employees is a weighted 
average of the proportions of employer-managers and employees in firms of that size, which, from Results 1.a) and 1.b), are given by $\left(L_{\min } / 250\right)^{\frac{a \beta}{1+\beta}}$ and $\left(L_{\min } / 250\right)^{\frac{\beta(a-1)-1}{1+\beta}}$ respectively. The three equations with real data on sizes of occupational groups and employment in large firms, used in the calibration exercise, are then formulated as follows:

$$
\begin{gathered}
\Gamma\left(e_{1}\right)=1-\left(\frac{b}{e_{1}}\right)^{a}=0.79 \\
1-\Gamma\left(e_{2}\right)=\left(\frac{b}{e_{2}}\right)^{a}=0.085 \\
\frac{0.085\left(\frac{L_{\text {min }}}{250}\right)^{\frac{a \beta}{1+\beta}}+0.79\left(\frac{L_{\text {min }}}{250}\right)^{\frac{\beta(a-1)-1}{1+\beta}}}{0.875}=0.25
\end{gathered}
$$

The values of $e_{1}, e_{2}$ and $L_{\min }$ in these equations must satisfy the market equilibrium conditions summarized in equations (12) to (14), which will also be part of the calculation of the equilibrium. Altogether, we have a system of six equations that must be solved numerically to obtain the values of the three parameters, $a, b$, and $\beta$. Appendix $\mathrm{B}$ shows the full set of equations and provides some additional technical details of the calculations. The results of the calibration give $a=4.78, b=3.27$, and $\beta=0.36$; together with $e_{1}=$ $4.53, e_{2}=5.48$, and $L_{\min }=1.94$. The list of parameter values is completed with $c=0.12$, $\theta=1, \mu=0.75$ and $\rho=0.5$.

\section{Robustness}

There are two parameters, $\mu$ and $\rho$, whose values have not been directly calibrated from observed data and taken from the results of calibrations with data from other countries. For robustness purposes, we examine the range of values of the parameters for which, keeping the other parameters constant, the proportions of the occupied in each occupational group in the new market equilibrium are close to the observed ones in Table 1. When $\mu$ is reduced from 0.75 in the base scenario to 0.70 , i.e. more capital-intensive technology, keeping the remaining parameters at their base values, the equilibrium 
occupation rates are $7.9 \%$ employers and 16\% solo entrepreneurs, compared with the observed $8.5 \%$ and $12.5 \%$, respectively (Table 1 ). More capital-intensive production technology increases the net income of the solo entrepreneurs more than do employers' profits, because the former have a limited amount of direct labor input available.

Additionally, we recalibrate the values of parameters $a$ and $b$ with $\mu=0.7$, keeping the rates of employers and solo entrepreneurs equal to those observed in the economy. We find that the observed occupational rates can be replicated in the base model by simply changing the minimum value of the distribution of skills, from $b=3.27$ to 3.62 and keeping $a$ and $\beta$ unchanged. Except for modest changes in the number of solo entrepreneurs, the results of the calibration can be considered reasonably robust for values of $\mu$ in the range between 0.7 and 0.75 .

Lower values of $\rho$, so that the elasticity of substitution approaches one (the Cobb Douglass production function), produce effects similar to reducing $\mu$ : the number of solo entrepreneurs increases and the number of employer-managers decreases. Greater elasticity of substitution increases the income of solo entrepreneurs. Since their labor input is fixed, greater elasticity of substitution allows for the use of more capital input in production and increases the output. In the range of values of $\sigma$ between the base case 0.67 and 1 , keeping the remaining parameters unchanged, the only endogenous variable sensitive to the value of the elasticity of substitution is again the number of solo entrepreneurs. For values of the elasticity of substitution above 1, the fit to the observed number of solo entrepreneurs and employer-managers would require a recalibration of the values of parameters $a$ and $b$.

\subsection{Comparison with observed distributions of firm sizes and occupied individuals}

Table 2 presents the distributions of firm size and the occupied in these firms, both observed and predicted from the model. The size classes, in number of employees, are defined as they appear in the official statistics: micro (1-9), small (10-49), medium (50$249)$ and large $(>250)$.

(TABLE 2) 
The large majority of Spanish firms with employees, up to $90.7 \%$ in 2013 , have fewer than 9 employees (micro firms). Only $1.56 \%$ of the firms with employees have 50 or more employees in that year. The distribution of occupied individuals in size classes of firms is more homogeneous than that of number of firms, but differences persist; the size classes of firms with higher proportion of the occupied are the micro, $40.7 \%$, and large, $26.16 \%$, and the lowest the medium with $13.51 \%$. The average number of the occupied per firm with employees is around 8. These patterns in the distribution of firms and occupied individuals in firm size classes are found in all OECD countries (OECD, 2014), but the Southern European countries, Spain, Italy, and Greece, are among the countries with higher proportions of micro and small firms and smaller average size of firms with employees. In Germany, for example, 3\% of firms have 50 or more employees and constitute $57 \%$ of the occupied; the average size of firms is more than twice that of Spanish firms. Axtell (2001) reports an average size of firms with employees of 22 for the US.

The distributions of firm sizes and employees in these firms vary over time. In the expansion year (2005), the proportions of firms in the size classes of 50 or more employees are higher than in 2013, at the peak of the crisis. The proportion of individuals occupied in the largest size firms increases as the crisis advances (from 2009 to 2013). In periods of expansion, the growth of small firms takes place to a greater extent by hiring employees than by increasing the number of firms. In periods of crisis, the reverse appears to occur, the loss of employees in small firms is higher than the contraction in the number of small firms. The numbers of medium and large firms decline by proportionally more in the crisis, but the remaining firms reduce employment by a lesser amount than the employment lost in small firms.

The comparison of predicted and observed distributions of firm sizes and occupied individuals confirms that the model can explain the Spanish data on firm sizes and sizes of occupational groups reasonably well. Notice that, in the calibration, we only use one data point of the distribution of employees in firms of the different size classes (employees in firms with 250 employees or more). Moreover, the number of firms with employees (approximately 1.5 million) reported in Table 2 is higher than the sum of managers and employers (approximately equal to 1.2 million), reported in Table 1, because there are employers-business owners with more than one firm. In the calibration 
of the parameters, we use data from Table 1 because the model explains occupational choices, not the decision on the number of firms-legal entities with which to conduct the businesses. This difference in the number of firms, legal entities, and entrepreneurmanagers, will be reflected in certain discrepancies between the observed and predicted proportions of firms in Table 2.

\section{COMPARATIVE STATIC ANALYSIS}

There are three main empirical regularities that the occupational choice model presented here can help us to understand: i) the cross-countries positive correlation between average size of firms and per capita income; ii), the evidence that the TFP of firms increases with their size; and iii) the inclusion of size of firms among the economic variables that follow a power law. In terms of the variables of the model, the first piece of empirical evidence refers to the correlation between the average size of firms with employees, ASF, in Result 1.d), equation (17), and total output produced, $T Y_{T}^{*}$. The second piece of evidence implies that the TFP value, $\theta g(e)=\theta e$, for skills, $e \geq e_{2}$, increases with $L$, the size of the firm for $L \geq L$ min. Finally, the properties of the distribution of firm sizes, and particularly if it is a power law or not, depend on the properties of the upper tail of the distribution of skills.

\subsection{Average size of firms and labor productivity of the economy}

Since the average size of firms and output per occupied individual are endogenous variables, the correlation between the two must be the result of changes of the sign in the values of the two variables, from changes in the values of the exogenous parameters of the model. The comparative static analysis cannot be performed analytically, because the equations that characterize the equilibrium (expressions [A3]-[A5] in Appendix A) have no closed-form solution and are too complex ${ }^{6}$. Therefore, we have calculated numerically the sign of the derivatives of the endogenous variables of the model for 20,000

\footnotetext{
${ }^{6}$ Suppose, for example, that we want to analyse the effect of parameter $\beta$ on total output, $T Y_{T}^{*}$. The analytical expression of the derivative of $T Y_{T}^{*}$ with respect to $\beta$ (computed with the software Wolfram Mathematica) has thousands of terms, which have different signs and depend on seven exogenous parameters and three endogenous variables. It is humanly impossible to prove whether the sign of this derivative is positive or negative.
} 
configurations of reasonable values of the parameters: $a$ from 3 to 100, $\beta$ from 0 to $0.5, b$ from 0 to $3, c$ from 0.01 to 0.20 , and $\mu$ from 0.5 to 0.9 .

Table 3 shows a sample of the results obtained from numerical calculations around the combination of parameter values calibrated with Spanish data. In particular, each row in Table 3 shows the percentage change in the selected endogenous variables resulting from a 1 percentage point change in the values of the parameter (columns) keeping the remaining parameters at their base values (elasticity). For example, the first number in the table, $3.13 \%$, is the percentage increase in the number of solo entrepreneurs when the value of parameter $\beta$ increases by $1 \%$ (from 0.36 in the base model to 0.3636 ). The calculations of the derivatives for the 20,000 configurations of the parameters all confirm the signs in Table 3.

In addition, we have solved for a closed solution of the average size of firms and total output produced in the simple case of no capital input, only employers and employees, and Pareto distribution of skills, and have analytically performed comparative static analysis of changes of the two variables to changes of the exogenous parameters, primarily $a$ and $\beta$. The analytical comparative static results of this simplified model also confirm the signs shown in Table 3 , for the reduced set of exogenous parameters.

The endogenous values of sizes of occupational groups, output, and sizes of firms, are highly sensitive to changes in organizational size diseconomies, $\beta$, and to the concentration of skills in the Pareto distribution, $a$. Higher $\beta$, and higher $a$, each separately, reduce the total output produced (labor productivity), increase the number of firms, lower their average size, and reduce the number of individuals occupied in large firms. Table 3 shows that, for practically all the exogenous parameters, the sign of the variation in output from increasing the value of one of them is the same as the sign of the variation in the chosen measure of size of the firms. The only exception is the increase in $b$, the lower bound in the distribution of skills that causes an increase in output and a decrease in the average size of firms with employees. This means that the empirical evidence showing a positive association in cross-country data between average sizes of firms and average productivity (output per occupied individual) can be generated by cross-country differences in the values of one or several of the exogenous parameters of the model. 
In this respect, the IMF and OECD repeatedly include, in their reports on the Spanish economy, the recommendation of increasing average size of firms as a way of increasing average labor productivity in the Spanish economy. Currently, GDP per hour worked in Spain is $85 \%$ of that of Germany and $78 \%$ of the GDP per hour in the US (OECD). From the market equilibrium, calculated with the calibrated values of the parameters for Spain, to approximately double the number of employees per entrepreneur-manager, average size of firms when the firm is defined as a management unit, from the current value of 9.5 employees to 20 , the value of $\beta=0.36$ would have to be reduced to $\beta=0.312$ (all other parameters being equal). With the lower value of the organization size diseconomies parameter, the total output produced, the average labor productivity of the economy in the context of the model, would increase by $17 \%$.

The average size of firms is also very sensitive to the concentration of the distribution of entrepreneurial skills, parameter $a$. To double the average size of firms with employees, 20 employees per employer-manager, the value of the parameter $a$ must change from the actual value of $a=4.78$ to $a=4.14$ (all other parameters being equal). The total output produced, average productivity, would increase by 55\%. Lower values of the parameter $a$ imply more individuals in the upper tail of the distribution of entrepreneurial skills (greater dispersion in the population); in this case, with $a=4.14$ the average skills of entrepreneurs in the top $1 \%$ of the distribution increases with respect to the current average, as do the sizes and productivity of the firms they manage.

Table 3 also shows the sensitivity of the sizes of occupational groups of solo entrepreneurs and entrepreneur-managers to changes in the exogenous parameters. The relative sizes of both groups change in the same direction in response to changes in the values of parameters $\beta$ and $a$. However, changes in the values of the lower bound of the distribution of skills, $b$, the cost of capital, $c$, the intensity of labor in production, $\mu$, the elasticity of substitution between direct labor and capital, $\rho$, and the general TFP of the economy, $\theta$, all give opposite signs of the resulting changes in the equilibrium proportions of solo entrepreneurs and entrepreneur-managers, with the values being higher for the solo entrepreneurs. This is both an additional justification of why the two groups of 
entrepreneurs should be treated separately, and an explanation of why the two can show different signs in the correlations with the GDP per capita of countries.

\subsection{Size of firm and TFP}

A generally accepted economic premise is that market competition will force inefficient firms out of the market and all surviving ones will then converge to similar levels of productivity and costs. However, the empirical evidence seems contrary to this prediction and significant differences in productivity, labor and TFP, persist among firms, even in the same industry (Hsieh and Klenow, 2009; Syverson, 2011). One common explanation of the observed heterogeneity in the productivity of firms is that inefficient entrepreneurs combined with market distortions, such as taxes on the use of inputs, and regulations, lead to misallocations of production resources (Banerjee and Duflo, 2005; Restuccia and Rogerson, 2008; Guner et al., 2008; Hsieh and Klenow, 2009).

Result 1.e) and equation (18), according to which the distribution of TFP of firms is a linear transformation $(\theta e)$ of the left-truncated distribution of entrepreneurial skills in the population (truncated at $e_{2}$ ), provide an alternative explanation to the heterogeneity observed in TFP: firms differ in TFP because they are managed by entrepreneurs of different entrepreneurial skills. The persistent heterogeneity in the TFP of firms associated with differences in the entrepreneurial skills of their entrepreneurs-managers is compatible with intense competition in the product markets and with outputmaximizing allocations of resource inputs within a firm and across firms.

Differences in the quality of entrepreneurial skills among entrepreneurs are difficult to observe empirically, but one reasonable assumption is that the level of skills will go handin-hand with how well firms are actually managed. Recent research has documented substantial differences in the quality of management of firms around the world, both within countries and across countries (Bloom and Van Reenen, 2007). Follow-up research with the same database also shows that quality of management is positively correlated with the size of the firm, and that higher quality has a positive effect on the TFP of firms (Bloom et al., 2014). 
In the market equilibrium from occupational choices, individuals in the upper tail of the distribution of skills will choose to work as entrepreneur-managers and, from equations (10) and (11), within this occupational group, those with higher skills will employ a greater volume of inputs, labor, and capital, and will produce more output than firms with less-skilled managers. Finally, from Result 1.e) and the discussion in section 5.1, we know that the distribution of TFP of firms matches an increasing transformation of the distribution of skills of their entrepreneur-managers. Therefore, the results of the model explain the positive association between the size of the firm and its TFP as the consequence of, first, that the entrepreneurs of higher skills command a larger volume of resources in the market equilibrium; and, second, the level of skills of the entrepreneurmanager directly determines the TFP of the firm.

Moral-Benito (2016), with data from individual Spanish firms, confirms that the estimated TFP of firms in the sample increases with their size, in line with evidence found in other studies with firms from other countries. From Moral-Benito (2016, Table 2), the average TFP of small, medium, and large firms, relative to the average TFP of micro firms are 1.6, 2.5, and 5.7, respectively. With the distribution of equation (18) and the calibrated values of the parameters, the estimated average TFP of solo entrepreneurs, micro, small, medium, and large firms, are 0.77, 1 (normalized value), 1.5, 2.4, and 4, respectively. The predicted average values of TFP of the size classes are very much in line with the estimations of Moral-Benito (2016) with real data from Spanish firms ${ }^{7}$.

\subsection{Power laws and the missing middle in the distribution of firm sizes}

There are two regularities in the empirical data on distribution of firm sizes that are often highlighted in research and policy analysis: first, the density of the distribution of firm sizes is a decreasing and convex function of the value of the size variable (for example, number of employees). Second, the proportions of occupied persons in the size classes of small and large firms are greater than the proportion of the occupied in middle-sized

\footnotetext{
${ }^{7}$ Hsieh and Klenow (2009) find that their estimated TFP for the firm in the 90th percentile of the size distribution of plants in the United States is 8.8 times the TFP estimated for the plant in the 10th percentile (22.4 for India and 11.5 for China). It is much higher than the ratio estimated here, 1.7, although in the calculations they assume constant returns to scale, while in our model, returns to scale are decreasing.
} 
firms. A simple observation confirms that the Spanish data in Table 2 shares these regularities.

The decreasing and convex with size density of the distribution of firms has led to the inclusion of the variable size of the firm in the class of economic variables that belong to the family of power laws (Axtell, 2001; Gabaix, 2016). The greater concentration of occupied individuals at the extremes of the distribution has been referred to as the "missing middle" (Hsieh and Olken, 2014). In this section, we reconcile these regularities with the predictions from occupational choice models.

A random variable $x$ follows a power law distribution if the elasticity of the probability of the value of the variable being higher or equal than $x$, to the value of $x$, is constant for all $x$ (Gabaix, 2016). In the context of this paper, $x$ is the size (number of employees, $L$ ) of the firm. The Pareto and the Zipf distributions satisfy the condition of constant elasticity; in fact, the Zipf distribution is considered a special case of Pareto distribution with elasticity equal to one. The density functions of power law distributions are decreasing and convex with the value of the random variable.

The theoretical distribution of firm sizes derived from the occupational choice model in Section 3 is a Pareto distribution expressed by equation (15):

$$
\operatorname{Pr}\left[L \geq L_{i}\right]=1-\Gamma_{\% \text { firms }}\left(L_{i}\right)=\left(\frac{L_{\min }}{L_{i}}\right)^{\frac{a \beta}{1+\beta}}, \quad \text { for } L_{i} \geq L_{\min }=L^{*}\left(e_{2}, w^{*}\right)
$$

Figure 2 shows the representation of the cumulative distribution (left) and the density functions (right) of firm sizes, from the values of the parameters calibrated with Spanish data $(a=4.78$ and $\beta=0.36)$ and power parameter $a \beta /(1+\beta)=1.265$.

Axtell (2001) studies the distribution of firm sizes in the US with census data and empirically estimates a power parameter value of 1.059. Then, Axtell concludes that the distribution of firm sizes in the US unequivocally follows a Zipf distribution (power parameter equal to one). The power parameter of the distribution of firm sizes in the US, 1.059 , is then lower than the one inferred from the calibrated values of the parameters for 
the distribution of Spanish firms, 1.265. Figure 3 shows the Zipf-plot distributions of firm size, $\ln \left[1-\Gamma_{\% \text { firms }}(L)\right]$, as a function of $\ln [L]$, for the values of the power parameter 1.059, US, and 1.265, Spain. A steeper slope in absolute value implies size distributions with a greater density of firms in the lower tail of the distribution and, therefore, distribution of firms of smaller average size. The Zipf-plots confirm that firm sizes in Spain are smaller than in the US. From the parameters that determine the values of the power parameters, the differences in firm size for the two countries can be explained by greater organizational size diseconomies and/or higher concentration of distribution of skills in Spain than in the US.

The empirical evidence lets Axtell (2001, p. 1818) to the conclusion that "the Zipf distribution of firm sizes is a target that any empirically-accurate theory of the firm must hit". The model of production and organization of firms, where entrepreneurs provide inputs in the form of quality of strategic decisions and supervision of the use of direct inputs - labor and capital at the job level - together with a competitive market allocation of entrepreneurial skills through occupational choices, responds to the Axtell request. Moreover, the occupational choice models provide additional insights into the origin of the empirical regularity in the density of firm sizes.

From the theory in Section 2.5, the distribution of firm sizes is a power transformation of the left-truncated distribution of entrepreneurial skills in the population (truncated at $e_{2}$ ). Since the distribution of skills is a Pareto-distribution, and has the property of a power law, the distribution of firm sizes will also be a power law with a different power parameter than the distribution of skills. But, what if the distribution of skills were normal or lognormal? The equilibrium from occupational choice implies that all individuals working as entrepreneur-managers will be drawn from the upper tail of the distribution of skills, and that the number of employees under the direction of each entrepreneurmanager will increase with skills. The theoretical distribution of firm sizes will be a power function of the (truncated) upper tail of the normal or lognormal distribution of skills, but it will not be strictly a power law because the lognormal and normal distributions do not share the property of the power laws (constant power parameter). In a purely empirical approach, although the distribution of skills is not a power law, the density of firm sizes 
will continue to be a convex and decreasing function of size (number of employees) and the statistical fit of the Zipf plot to the data will most likely assure a high R2.

The point to bear in mind is that, for many distributions of skills, the empirical, observed distribution of firm sizes will be decreasing and convex with size, so it is most likely that the fit of the Zipf-plot to the data will give a high R2 in the statistical estimation, independently of whether the empirical data come from values of a true theoretical distribution of firm sizes, or not. The theories of the firm should not be subordinated to the presumption that the distribution of firm sizes follows a power law. Rather, the theory should guide the empirical research in identifying the conditions under which the hypothesis of the constant power parameter of the distribution is consistent with the theoretical model, and when it is not.

\section{The missing middle}

The dashed lines in Figure 2 show the distribution and density functions of employees as a function of the size of firms (number of employees), obtained from equation (16), and the values of the parameters calibrated from Spanish data. The distribution of employees also follows a power law with power parameter $[\beta(a-1)-1] /(1+\beta)=0.265$, i.e. the power parameter of the distribution of firm sizes minus one (Results 1.b) and 1.c) above). The density function of employees as a function of the size of the firm is then convex and always decreasing with size. Since the power parameter of the distribution of firms is higher than that of the distribution of employees, the density function of firms will be more convex than the density of employees, and the two density functions will intersect in a certain size value (close to 10 employees in this case).

The convex and smoothly decreasing density function of employees as a function of the size of the firm, contrasts with the evidence of Table 2 on the proportion of occupied in micro, small, medium, and large firms, decreasing from the micro to the medium sizes and increasing again in the class of large firms. This pattern of distribution of occupied individuals with high concentration in the size classes of micro and large firms, and low concentration of the occupied in mid-sized firms, repeats in distributions of firms in all countries and has been named the "missing middle". The missing middle has been attributed to the difficulty of micro and small firms to grow because of the lack of 
financial and other critical resources, and/or to incremental costs from complying with firm-size-dependent regulations applied to firms when they reach a certain size, for example 50 employees (Tybout, 2000; Kruger, 2013; Hsieh and Olken, 2014).

Figure 4 shows the distribution of employees as a function of size of the firm together with the representation of the proportions of employees in the size classes of 1-9 employees (micro), 10-49 employees (small), 50 to 249 employees (medium), and more than 249 employees (large). The figure confirms that there is no contradiction at all between the continuous decreasing density function of employees as a function of size, and the U-shaped representation of proportions of the occupied in classes of size of firms in Table 2. It all has to do with the way the bounds have been chosen to define the size classes, and the convexity of the continuous density function. Inferences on sizedependent obstacles to growth, and follow up of firm-size dependent policies to remove them from the comparatively low proportion of employment and activity in mid-sized firms, as defined in official statistics on the distribution of firm sizes, can then be misleading.

\section{CONCLUSION}

Empirical evidence such that i) average sizes of firms are positively correlated with per capita income of countries (Bento and Restuccia, 2016), and ii) that, within a country, larger firms are more productive, in terms of TFP, than small ones (Hsieh and Klenov, 2009, 2014; Moral-Benito, 2016), make the size of firms an important policy variable (OECD, 2014; IMF, 2015). Models such as the one presented in this paper make clear that the size of firms, their respective productivity, and the average productivity and size aggregated for the whole economy, are all endogenous variables that result from competition pressures among individuals, who make occupational choices of working as employees, solo entrepreneurs, or entrepreneur-managers. Firm-size-dependent policies per se, i.e. those that make increasing the sizes of firms a direct policy target, will not be effective in reaching the goal of increasing productivity and per capita income of countries if the underlying determinants of the distribution of firm sizes remain intact. Since self-employment is also used as an indicator of entrepreneurship, and proportions of solo self-employed and employers are endogenously determined, some of the conclusions from the paper can also illustrate and inform the debate around whether and 
when entrepreneurship contributes to economic development (Parker, 2009; Shane, 2009; van Praag and van Stel, 2013).

Occupational choice models offer a conceptual framework to examine the determinants of firm sizes and productivity and, therefore, identify possible policy targets among the factors that ultimately lead to the observed sizes of firms. In particular, the model presented here points to factors whose differences across countries can explain differences in the average size of firms and labor productivity: i) the properties of the distribution of entrepreneurial skills in the population; ii) the properties of the representative production technology (degree of technical scale economies and capital intensity, elasticity of substitution between labor and capital, general level of operating efficiency common to all firms); iii) the internal organization of firms, for example the efficient delegation of decision power in hierarchical organizations; and iv) the cost of capital. Among these factors, the preliminary comparative static results presented in this paper suggest that the equilibrium distribution of firm sizes is particularly sensitive to the values of the parameters of dispersion in the distribution of skills, and the degree of organizational size diseconomies. Prior research, mainly empirical, has focused on environmental, political, and institutional forces to explain differences in the size distribution of firms across countries (Davis and Henrekson, 1999; Kumar et al., 1999). However, the two factors highlighted here, the distribution of skills and the internal organization of firms, have been overlooked.

Prior research has demonstrated the usefulness of occupational choice models to evaluate the social costs and benefits of market frictions resulting from taxes and minimum wages (Medrano-Adán et al., 2015); firm-size dependent policies that unintentionally increase the external cost of growth of firms (Garicano et al., 2016), and discriminatorily tax capital and/or labor (Guner et al., 2008). Public policies can alter the distribution of entrepreneurial skills through immigration laws and through education systems that foster diversity and experimentation. The internal costs of growth of firms are lower when trust reduces agency costs, and when the individuals in lower hierarchical ranks have the skills demanded by the more complex problems they will face after the delegation. Combining policies in these directions, education for diversity, and trust enforcement, and with wellfunctioning markets for the control of productive resources, which, in turn, facilitate 
skilled management teams who can effectively manage more resources than less-skilled ones, should contribute gradually to higher productivity and social welfare.

The repeated shape of a decreasing and convex density function of firm size in empirical studies has led to the inclusion of firm size as an economic variable whose behavior is described by a power law (Gabaix, 2016). Moreover, the reiteration in the empirical regularity has been used to justify the assertion that theories of the firm should take the power law distribution of firm size as a target to fit (Axtell, 2001). A similar argument could be used to say that firm-size dependent policies should be constrained by the fact that the distribution of firm size is a power law. Our analysis provides theoretical conditions under which the size distribution of firms can be represented by a power law. The relatively strict conditions contrast with the generalized empirical evidence, across countries, of distributions of firm size, decreasing and convex with size, that suggest that the power law is universal. The apparent contradiction is resolved in knowing that the true distribution of firm size corresponds to a monotonic transformation of the (truncated) upper-tail of the distribution of entrepreneurial skills in the population. If the monotonic transformation is a power function, and the distribution of skills is a power law, then distributions of firm size will be a conditioned power law. Otherwise, the power law will be an approximation, generally a good approximation, in terms of statistical goodness of fit, of a general distribution.

Empirical regularities such as the power law shape of the distribution of firm size, and the relatively low concentration of occupation and activity in small and mid-sized firms, compared with concentration in micro and large firms per se, as identified in the official statistics on firm sizes, say nothing about potential market frictions that increase the cost of growth of firms, and/or impose obstacles to higher labor productivity. A theory of the determinants of the distribution of firm sizes and TFP in friction-free markets provides a benchmark from which to define public policies that target the educational, technological, and management practices that can change the size distribution of firms in the same direction, as the economy becomes more productive.

\section{REFERENCES}

Axtell, R. (2001). "Zipf Distributions of US Firm Sizes". Science, 293(5536), 1818-1820. https://doi.org/10.1126/science.1062081 
Banco de España (2014). Central de Balances 2013. Resultados anuales de las empresas no financieras, Banco de España, Madrid.

Banerjee, A., and Duflo, E., (2005). "Growth Theory through the Lens of Development Economics", In P. Aghion and S. N. Durlauf (eds.), Handbook of Economic Growth, Volume 1A, Chap. 7, pp. 453-572. Elsevier BV. https://doi.org/10.1016/S1574-0684(05)01007-5

Bento, P., and Restuccia, D. (2016). Misallocation, Establishment Size and Productivity. NBER Working Paper No. 22809. https://doi.org/10.3386/w22809

Blanchflower, D. (2004). "Self-employment: More May not Be Better". Swedish Economic Policy Review, 11(2), 15-73.

Blau, D. M., 1987, “A Time-Series Analysis of Self- Employment in the United States". Journal of Political Economy, 95(3), 445-467. https://doi.org/10.1086/261466

Bloom, N., and Van Reenen, J. (2007). "Measuring and Explaining Management Practices across Firms and Countries". Quarterly Journal of Economics, 122(4), 1351-1408. https://doi.org/10.1162/qjec.2007.122.4.1351

Bloom, N., Lemos, R., Sadun, R., Scur, D., and Van Reenen, J. (2014). "The New Empirical Economics of Management". Journal of the European Economic Association, 12(4), 835-876. https://doi.org/10.1111/jeea.12094

Bosma, N., Jones, K., Autio, E., and Levie, J. (2008). Global Entrepreneurship Monitor: 2007 Executive Report. Wellesley, MA: Babson College and London: London Business School.

Branstetter, L., Lima, F., Taylor, L., and Venâncio, A. (2014). "Do Entry Regulations Deter Entrepreneurship and Job Creation? Evidence from Recent Reforms in Portugal". Economic Journal, 124(577), 805-832. https://doi.org/10.1111/ecoj.12044

Calvo, G., and Wellisz, S. (1980). “Technology, Entrepreneurs and Firm Size”. Quarterly Journal of Economics, 95(4), 663-678. https://doi.org/10.2307/1885486

Carree, M., van Stel, A., Thurik, R., and Wennekers, S. (2007). "The Relationship Between Economic Development and Business Ownership Revisited". Entrepreneurship and Regional Development, 19(3), 281-291. http://dx.doi.org/10.1080/08985620701296318

Carree, M., van Stel, A., Thurik, R., and Wennekers, S. (2002). "Economic Development and Business Ownership: An Analysis Using Data of 23 OECD Countries in the Period 1976-1996". Small Business Economics, 19(3), 271-290. https://doi.org/10.1023/A:1019604426387

Davis, S.J., and Henrekson, M. (1999). "Explaining National Differences in the Size and Industry Distribution of Employment". Small Business Economics, 12(1) 59-83. https://doi.org/10.1023/A:1008078130748

Gabaix, X. (2016) "Power Laws in Economics: An Introduction". Journal of Economic 
Perspectives, 30(1), 185-206. http://dx.doi.org/10.1257/jep.30.1.185

Garicano, L. (2000). "Hierarchies and the Organization of Knowledge in Production". Journal of Political Economy, 108(5), 874-904. https://doi.org/10.1086/317671

Garicano, L., and Rossi-Hansberg, E. (2006). "Organization and Inequality in a Knowledge Economy”. Quarterly Journal of Economics, 121(4), 1383-1435. https://doi.org/10.1093/qje/121.4.1383

Garicano, L., Lelarge, C., Van Reenen, J. (2016). "Firm Size Distortions and the Productivity Distribution: Evidence from France", American Economic Review, 106 (11), 3439-3479. http://dx.doi.org/10.1257/aer.20130232

Gollin, D. (2008). "Nobody's Business but My Own: Self-employment and Small Enterprise in Economic Development". Journal of Monetary Economics, 55(2), 219-233. https://doi.org/10.1016/j.jmoneco.2007.11.003

Guner, N., Ventura, G., and Xu, Y. (2008). "Macroeconomic Implications of SizeDependent Policies". Review of Economic Dynamics, 11(4), 721-744. https://doi.org/10.1016/j.red.2008.01.005

Gur, N. and Bjornskov, Ch. (2016) "Trust and Delegation: Theory and evidence". Journal of Comparative Economics doi.org/10.1016/j.jce.2016.02.002

Henrekson, M., and Johansson, D. (1999) "Institutional Effects on the Evolution of the Size Distribution of Firms”, Small Business Economics, 12(1), 11-23. https://doi.org/10.1023/A:1008002330051

Hopenhayn, H. (1992). "Entry, Exit, and Firm Dynamics in Long Run Equilibrium". Econometrica, 60(5), 1127-1150. https://doi.org/10.2307/2951541

Hsieh, Ch., and Klenow, P. (2009). "Misallocation and Manufacturing TFP in China and India". Quarterly Journal of Economics, 124(4), 1403-1448. https://doi.org/10.1162/qjec.2009.124.4.1403

Hsieh, Ch., and Klenow, P. (2014). "The Life Cycle of Plants in India and Mexico". Quarterly Journal of Economics, 129(3), 1035-1084. https://doi.org/10.1093/qje/qju014

Hsieh, Ch., and Olken, B. (2014). "The Missing 'Missing Middle"'. Journal of Economic Perspectives, 28(3), 89-108. http://dx.doi.org/10.1257/jep.28.3.89

Idson, T., and Oi, W. (1999). "Workers Are More Productive in Large Firms". American Economic Review, 89(2), 104-108. https://doi.org/10.1257/aer.89.2.104

IMF (2015), "Obstacles to firm growth in Spain”. In Spain. Selected Issues. IMF Country Report No. 15/233. August 2015. International Monetary Fund Washington, D.C. https://www.imf.org/external/pubs/ft/scr/2015/cr15233.pdf

Jovanovic, B. (1982). "Selection and the Evolution of Industry". Econometrica, 50(3), 649-670. https://doi.org/10.2307/1912606 
Jovanovic, B. (1994). "Firm Formation with Heterogeneous Management and Labor Skills". Small Business Economics, 6(3), 185-191. https://doi.org/10.1007/BF01108287

Kihlstrom, R., and Laffont, J. (1979). "A General Equilibrium Entrepreneurial Theory of Firm Formation Based on Risk Aversion”. Journal of Political Economy, 87(4), 719-749. https://doi.org/10.1086/260790

Krueger, A.O. (2013). “The Missing Middle”. In N.C. Hope, A. Kochar, R. Noll and T.N. Srinivasan (Eds.) Economic Reform in India: Challenges, Prospects, and Lessons, pp. 299-318. Cambridge: Cambridge University Press.

Kumar, K., Rajan, R., and Zingales, L. (1999). What Determines Firm Size? NBER Working Paper No. 7208. https://doi.org/10.3386/w7208

Lucas, R. (1978). "On the Size Distribution of Business Firms". The Bell Journal of Economics, 9(2), 508-523. https://doi.org/10.2307/3003596

Medrano-Adán, L., Salas-Fumás, V., and Sanchez-Asin, J.J. (2015) "Heterogeneous Entrepreneurs from Occupational Choices in Economies with Minimum Wage". Small Business Economics, 44(3), 597-619. https://doi.org/10.1007/s11187-0149610-4

Ministerio de Industria, Energía y Turismo (2014). Retrato de las PYME 2013. MIET, Dirección General de Industria y de la Pequeña y Mediana Empresa, Madrid.

Moral-Benito, E. (2016). Growing by Learning: Firm Level Evidence on the SizeProductivity Nexus, Banco de España, D.T. No. 1613. http://www.bde.es/f/webbde/SES/Secciones/Publicaciones/PublicacionesSeriada s/DocumentosTrabajo/16/Fich/dt1613e.pdf

OECD (2014). "Moving towards a more dynamic business sector in Spain". In OECD Economic Surveys: Spain 2014, pp. 105-146. OECD Publishing. http://dx.doi.org/10.1787/eco_surveys-esp-2014-en

Onji, K. (2009). "The Response of Firms to Eligibility Thresholds: Evidence from the Japanese Value-Added Tax”. Journal of Public Economics, 93(5-6), 766-775. https://doi.org/10.1016/j.jpubeco.2008.12.003

Parker, S. (2009). The Economics of Entrepreneurship, Cambridge, UK: Cambridge University Press.

Penrose, E. T. (1959). Theory of the Growth of the Firm, J. Wiley \& Sons, New York.

Restuccia, D., and Rogerson, R. (2008). "Policy Distortions and Aggregate Productivity with Heterogeneous Plants". Review of Economic Dynamics, 11(4), 707-720. https://doi.org/10.1016/j.red.2008.05.002

Rosen, S. (1982). "Authority, Control, and the Distribution of Earnings". The Bell Journal of Economics, 13(2), 311-323. https://doi.org/10.2307/3003456

Salas-Fumás, V., Sanchez-Asin, J.J., and Storey, D. (2014). “Occupational Choice, 
Number of Entrepreneurs and Output: Theory and Empirical Evidence with Spanish Data". Series, Journal of the Spanish Economic Association, 5(1), 1-24. https://doi.org/10.1007/s13209-013-0103-5

Schivardi, F., and Torrini, R. (2008). "Identifying the Effects of Firing Restrictions through Size-Contingent Differences in Regulation”. Labour Economics, 15(3), 482-511. https://doi.org/10.1016/j.labeco.2007.03.003

Shane, S. (2009). "Why Encouraging More People to Become Entrepreneurs is Bad Public Policy". Small Business Economics, 33(2), 141-149. https://doi.org/10.1007/s11187-009-9215-5

Syverson, Ch. (2011). "What Determines Productivity?" Journal of Economic Literature, 49(2), 326-365. https://doi.org/10.1257/jel.49.2.326

Tybout, J.R. (2000). "Manufacturing Firms in Developing Countries: How Well Do They Do, and Why?" Journal of Economic Literature, 38(1), 11-44. https://doi.org/10.1257/jel.38.1.11

Van Praag, M., and van Stel, A. (2013). "The More Business Owners, the Merrier? The Role of Tertiary Education". Small Business Economics, 41(2), 335-357. https://doi.org/10.1007/s11187-012-9436-x 


\section{Appendix A \\ The market equilibrium solution}

From the main text, in the market equilibrium:

i. Each agent makes the occupational choice (employee, solo entrepreneur, or employer-manager) that results in a higher "rent".

ii. Aggregate labor demand equals aggregate labor supply (this condition determines the equilibrium wage).

Both conditions are interrelated. The occupational choice depends on the wage that is set in the labor market, and the labor supply and demand depend on the individual occupational choices.

For a given wage $w$, the occupational choice of an individual with entrepreneurial skills $e$ may be written as:

$$
\operatorname{Max}[w, R(e), \Pi(e)]
$$

where $\Pi(e)$ and $R(e)$ are, respectively, the net revenues of the solo entrepreneur and the profits of employers, as functions of her respective level of skill, equations (9) and (11) in the main text. There exist two levels of skill $e_{1}$ and $e_{2}$ (see Figure 1) such that

$$
\operatorname{Max}[w, R(e), \Pi(e)]=\left\{\begin{array}{cc}
w & \text { for } e \leq e_{1} \\
R(e) & \text { for } e_{1} \leq e \leq e_{2} \\
\Pi(e) & \text { for } e \geq e_{2}
\end{array}\right.
$$

and

$$
\begin{gathered}
w=R\left(e_{1}\right) \\
R\left(e_{2}\right)=\Pi\left(e_{2}\right)
\end{gathered}
$$

Individuals with skills $e<e_{1}$ will choose to work as employees, individuals with skills $e_{1}$ $<e<e_{2}$ will prefer to be solo entrepreneurs, and individuals with skills $e>e_{2}$ will become 
employer-managers. $e_{1}$ is the level of entrepreneurial skill of the (unique) individual who is indifferent between working as an employee and becoming a solo entrepreneur. Analogously, $e_{2}$ is the level of entrepreneurial skills of the (unique) individual who is indifferent between becoming a solo entrepreneur and working as an employer-manager.

The occupational choices determine the aggregate labor supply $S(w)=\int_{b}^{e_{1}\left(w^{*}\right)} d \Gamma(e)$, and the aggregate labor demand $\left.D(w)=\int_{e_{2}\left(w^{*}\right)}^{+\infty} L\left(e ; w^{*}, c\right) d \Gamma(e)\right)$. In equilibrium the two must be equal, so the market equilibrium conditions are given by the three equations:

$$
\begin{gathered}
w=R\left(e_{1}\right) \\
R\left(e_{2}\right)=\Pi\left(e_{2}\right) \\
\int_{b}^{e_{1}} d \Gamma(e)=\int_{e_{2}}^{+\infty} L(e ; w, c) d \Gamma(e)
\end{gathered}
$$

where $L(e, w, c), \Pi(e)$ and $R(e)$ are given by (10), (11) and (9) in the main text, and $\Gamma(e)$ is the Pareto-cumulative distribution function with parameters $(a, b)$. After substituting these equations (demand for employees, profits of employers and revenues of the solo self-employed), and doing some calculations, we obtain the following system of equations in $\left(e_{1}, e_{2}, w\right)$ that characterize the equilibrium:

$$
\begin{gathered}
w=\left(\left(\theta e_{1}\right)^{\frac{\rho}{1+\rho}}\left(\frac{c}{1-\mu}\right)^{\frac{1}{1+\rho}}-c\right)\left(\frac{1}{\mu}\left(\frac{\theta(1-\mu) e_{1}}{c}\right)^{\frac{\rho}{1+\rho}}-\frac{(1-\mu)}{\mu}\right)^{\frac{1}{\rho}} \\
\frac{\left(\left(\theta e_{2}\right)^{\frac{\rho}{1+\rho}}\left(\frac{c}{1-\mu}\right)^{\frac{1}{1+\rho}}-c\right)}{\left(\frac{1}{\mu}\left(\frac{\theta(1-\mu) e_{2}}{c}\right)^{\frac{\rho}{1+\rho}}-\frac{(1-\mu)}{\mu}\right)^{\frac{-1}{\rho}}}=\frac{\beta \theta^{\frac{1}{\beta}}(1-\beta)^{\frac{1-\beta}{\beta}} e_{2}^{\frac{\beta+1}{\beta}}}{\left((1-\mu)^{\frac{1}{1+\rho}} c^{\frac{\rho}{1+\rho}}+\mu^{\frac{1}{1+\rho}} w^{\frac{\rho}{1+\rho}}\right)^{\frac{(1-\beta)(1+\rho)}{\rho \beta}}}
\end{gathered}
$$




$$
\frac{\beta a b^{a}}{\beta(a-1)-1} \frac{\theta^{\frac{1}{\beta}}(1-\beta)^{\frac{1}{\beta}}\left(\frac{\mu}{w}\right)^{\frac{1}{1+\rho}}}{\left.(1-\mu)^{\frac{1}{1+\rho}} c^{\frac{\rho}{1+\rho}}+\mu^{\frac{1}{1+\rho}} w^{\frac{\rho}{1+\rho}}\right)^{\frac{\rho+1-\beta}{\rho \beta}}} e_{2}^{\frac{1-\beta(a-1)}{\beta}}=\left(1-\left(\frac{b}{e_{1}}\right)^{a}\right)
$$

There is no closed-form solution to this non-linear system of equations. Although these equations are complex, we can prove existence and uniqueness ${ }^{8}$ of equilibrium, provided that the necessary condition $\beta(a-1)>1$ is satisfied, and we can solve them numerically, implicitly defining the equilibrium values of $e_{1}, e_{2}$, and $w$ as functions of the 7 exogenous parameters

$$
e_{1}^{*}(\theta, \mu, c, \rho, \beta, a, b), \quad e_{2}^{*}(\theta, \mu, c, \rho, \beta, a, b) \text {, and } w^{*}(\theta, \mu, c, \rho, \beta, a, b) .
$$

Alternatively, we can express the equilibrium values of $w$ and $e_{2}$ as functions of $e_{1}$, and then find the equilibrium value of $e_{1}$ by solving a single equation. Proceeding in this way, the equilibrium value of $w$ (as a function of $e_{1}$ ) is directly given by [A9] and the equilibrium value of $e_{2}$ is given by:

$e_{2}=\left(\left(1-\left(\frac{b}{e_{1}}\right)^{a}\right) \frac{(\beta(a-1)-1) f_{1}\left(e_{1}\right)}{\theta^{\frac{1}{\beta}}(1-\beta)^{\frac{1}{\beta}} \mu^{\frac{1}{\rho}} \beta a b^{a}}\left((1-\mu)^{\frac{1}{1+\rho}} c^{\frac{\rho}{1+\rho}}+\left[f_{1}\left(e_{1}\right)\right]^{\rho}\right)^{\frac{\rho+1-\beta}{\rho \beta}}\right)^{\frac{\beta}{1-\beta(a-1)}}$

where $f_{1}\left(e_{1}\right)=\left(\left(\frac{c \theta^{\rho} e_{1}^{\rho}}{1-\mu}\right)^{\frac{1}{1+\rho}}-c\right)^{\frac{1}{1+\rho}}\left(\left(\frac{\theta(1-\mu) e_{1}}{c}\right)^{\frac{\rho}{1+\rho}}-(1-\mu)\right)^{\frac{1}{\rho(1+\rho)}}$.

Finally, the equilibrium value of $e_{1}$ is given by the unique ${ }^{9}$ solution to the following equation that satisfies conditions $b \leq e_{1} \leq e_{2}$, and $w \geq 0$ :

\footnotetext{
${ }^{8}$ The proof is available upon request.

${ }^{9}$ In general, this equation has two positive solutions, but the largest one is not an equilibrium since the corresponding values of $e_{2}$ and $w$ do not satisfy the necessary conditions $b \leq e_{1} \leq e_{2}$, and $w \geq 0$.
} 


$$
\left(A_{4}\left(\frac{A_{2}\left(1-\left(b / e_{1}\right)^{a}\right) f_{1}\left(e_{1}\right)}{\left(A_{3}+\left[f_{1}\left(e_{1}\right)\right]^{\rho}\right)^{-A_{6}}}\right)^{A_{1}}-1\right)^{\frac{1+\rho}{\rho}}=\frac{\beta \mu^{\frac{1}{\rho}} \theta^{\frac{1}{\beta}}(1-\beta)^{\frac{1}{\beta}}}{c(1-\mu)^{\frac{1}{\rho}}} \frac{\left[A_{2}\left(1-\left(b / e_{1}\right)^{a}\right) f_{1}\left(e_{1}\right)\right]^{A_{5}}}{\left(A_{3}+\left[f_{1}\left(e_{1}\right)\right]^{\rho}\right)^{A_{6}\left(1-A_{5}\right)-1}}[\mathrm{~A} 7]
$$

where,

$$
\begin{aligned}
& A_{1}=\frac{-\beta \rho(1+\beta)}{(1+\rho)(\beta(a-1)-\tau)}<0, \quad A_{2}=\frac{(\beta(a-1)-1)}{\theta^{\frac{1}{\beta}}(1-\beta)^{\frac{1}{\beta}} \mu^{\frac{1}{\rho}} \beta a b^{a}}>0, \quad A_{3}=(1-\mu)^{\frac{1}{1+\rho}} c^{\frac{\rho}{1+\rho}}>0, \\
& A_{4}=\left(\frac{\theta^{\rho}}{c^{\rho}(1-\mu)}\right)^{\frac{1}{1+\rho}}>0, \quad A_{5}=\frac{-(\beta+1)}{(\beta(a-1)-1)}<0, \quad A_{6}=\frac{1+\rho-\beta}{\rho \beta}>0, \quad \text { and } \\
& f_{1}\left(e_{1}\right)=\left(\left(\frac{c \theta^{\rho} e_{1}^{\rho}}{1-\mu}\right)^{\frac{1}{1+\rho}}-c\right)^{\frac{1}{1+\rho}}\left(\left(\frac{\theta(1-\mu) e_{1}}{c}\right)^{\frac{\rho}{1+\rho}}-(1-\mu)\right)^{\frac{1}{\rho(1+\rho)}}
\end{aligned}
$$

This equation has no closed-form solution but can be solved numerically, implicitly defining the equilibrium value of $e_{1}$ as a function of the exogenous parameters

$$
e_{1}^{*}(\theta, \mu, c, \rho, \beta, a, b)
$$

Once the equilibrium value of $e_{1}$ is found, it is straightforward to obtain the equilibrium wage, the equilibrium value of $e_{2}$, and any other endogenous variable (labor supply, equilibrium number of employees, and so on). 


\section{Appendix B}

\section{Calibration of the parameters of the model}

The exogenous parameters of the model are $(\theta, \mu, c, \rho, \beta, a, b)$. In the main text, we justify the initial values for parameters $c=0.12, \theta=1, \rho=0.5(\sigma=2 / 3)$ and $\mu=0.75$. Therefore, we have parameters $a, b$, and $\beta$ remaining for calibration. For the calibration, we use information on the proportions of those employed as employees and as employers plus managers, together with information on the proportion of those occupied in firms with 250 employees or more, and the market equilibrium conditions of the model:

$$
\begin{gathered}
\Gamma\left(e_{1}\right)=1-\left(\frac{b}{e_{1}}\right)^{a}=0.79 \\
1-\Gamma\left(e_{2}\right)=\left(\frac{b}{e_{2}}\right)^{a}=0.085 \\
\frac{0.08\left(\frac{L_{\text {min }}}{250}\right)^{\frac{a \beta}{1+\beta}}+0.79\left(\frac{L_{\text {min }}}{250}\right)^{\frac{\beta(a-1)-1}{1+\beta}}}{0.875}=0.25
\end{gathered}
$$

where $L_{\min }=L\left(\mathrm{w} ; e_{2}\right)$ is given in result $1 . \mathrm{b}$, and $w, e_{1}$ and $e_{2}$ are given by the market equilibrium conditions, equations [A3] to [A5] of Appendix A. Substituting $L_{\min }$ the complete system of equations is:

$$
\begin{gathered}
1-\left(\frac{b}{e_{1}}\right)^{a}=0.79, \\
\left(\frac{b}{e_{2}}\right)^{a}=0.085, \\
0.875 \times 0.25=0.08\left(\frac{1}{250} \theta^{\frac{1}{\beta}}(1-\beta)^{\frac{1}{\beta}}\left(\frac{\mu}{w}\right)^{\frac{1}{1+\rho}}\left((1-\mu)^{\frac{1}{1+\rho}} c^{\frac{\rho}{1+\rho}}+\mu^{\frac{1}{1+\rho}} w^{\frac{\rho}{1+\rho}}\right)^{\frac{-\rho-1+\beta}{\rho \beta}} e_{2}^{\frac{\beta+1}{\beta}}\right)^{\frac{a \beta}{1+\beta}}+ \\
+0.79\left(\frac{1}{250} \theta^{\frac{1}{\beta}}(1-\beta)^{\frac{1}{\beta}}\left(\frac{\mu}{w}\right)^{\frac{1}{1+\rho}}\left((1-\mu)^{\frac{1}{1+\rho}} c^{\frac{\rho}{1+\rho}}+\mu^{\frac{1}{1+\rho}} w^{\frac{\rho}{1+\rho}}\right)^{\frac{-\rho-1+\beta}{\rho \beta}} e_{2}^{\frac{\beta+1}{\beta}}\right)^{\frac{\beta(a-1)-1}{1+\beta}},
\end{gathered}
$$




$$
\begin{aligned}
& w=\left(\left(\theta e_{1}\right)^{\frac{\rho}{1+\rho}}\left(\frac{c}{1-\mu}\right)^{\frac{1}{1+\rho}}-c\right)\left(\frac{1}{\mu}\left(\frac{\theta(1-\mu) e_{1}}{c}\right)^{\frac{\rho}{1+\rho}}-\frac{(1-\mu)}{\mu}\right)^{\frac{1}{\rho}}, \\
& \frac{\left(\left(\theta e_{2}\right)^{\frac{\rho}{1+\rho}}\left(\frac{c}{1-\mu}\right)^{\frac{1}{1+\rho}}-c\right)}{\left(\frac{1}{\mu}\left(\frac{\theta(1-\mu) e_{2}}{c}\right)^{\frac{\rho}{1+\rho}}-\frac{(1-\mu)}{\mu}\right)^{\frac{1}{\rho}}}=\frac{\beta \theta^{\frac{1}{\beta}}(1-\beta)^{\frac{1-\beta}{\beta}} e_{2}^{\frac{\beta+1}{\beta}}}{\left((1-\mu)^{\frac{1}{1+\rho}} c^{\frac{\rho}{1+\rho}}+\mu^{\frac{1}{1+\rho}} w^{\frac{\rho}{1+\rho}}\right)^{\frac{(1-\beta)(1+\rho)}{\rho \beta}}}, \\
& \frac{\beta a b^{a}}{\beta(a-1)-1} \frac{\theta^{\frac{1}{\beta}}(1-\beta)^{\frac{1}{\beta}}\left(\frac{\mu}{w}\right)^{\frac{1}{1+\rho}}}{\left((1-\mu)^{\frac{1}{1+\rho}} c^{\frac{\rho}{1+\rho}}+\mu^{\frac{1}{1+\rho}} w^{\frac{\rho}{1+\rho}}\right)^{\frac{\rho+1-\beta}{\rho \beta}}} e_{2}^{\frac{1-\beta(a-1)}{\beta}}=\left(1-\left(\frac{b}{e_{1}}\right)^{a}\right)
\end{aligned}
$$

After substituting $\theta=1, c=0.12, \mu=0.75$ and $\rho=0.5$ into these equations, we obtain the following equations system on six unknowns: $e_{1}, e_{2}, w, a, b$ and $\beta$.

$$
\begin{gathered}
1-\left(\frac{b}{e_{1}}\right)^{a}=0.79, \\
\left(\frac{b}{e_{2}}\right)^{a}=0.085 \\
0.875 \times 0.25=0.08\left(\frac{1}{250}(1-\beta)^{\frac{1}{\beta}}\left(\frac{0.75}{w}\right)^{\frac{2}{3}}\left((0.25)^{\frac{2}{3}} 0.12^{\frac{1}{3}}+0.75^{\frac{2}{3}} w^{\frac{1}{3}}\right)^{\frac{-1.5+\beta}{0.5 \beta}} e_{2}^{\frac{\beta+1}{\beta}}\right)^{\frac{a \beta}{1+\beta}}+ \\
+0.79\left(\frac{1}{250}(1-\beta)^{\frac{1}{\beta}}\left(\frac{0.75}{w}\right)^{\frac{2}{3}}\left((0.25)^{\frac{2}{3}} 0.12^{\frac{1}{3}}+0.75^{\frac{2}{3}} w^{\frac{1}{3}}\right)^{\frac{-1.5+\beta}{0.5 \beta}} e_{2}^{\frac{\beta+1}{\beta}}\right)^{\frac{\beta(a-1)-1}{1+\beta}},
\end{gathered}
$$




$$
\begin{gathered}
w=\left(e_{1}^{\frac{1}{3}}\left(\frac{0.12}{0.25}\right)^{\frac{2}{3}}-0.12\right)\left(\frac{4}{3}\left(\frac{0.75 e_{1}}{0.12}\right)^{\frac{2}{3}}-\frac{0.25}{0.75}\right)^{2}, \\
\frac{\left(e_{2}^{\frac{1}{3}}\left(\frac{0.12}{0.25}\right)^{\frac{2}{3}}-0.12\right)}{\left(\frac{1}{0.75}\left(\frac{0.25 e_{2}}{0.12}\right)^{\frac{1}{3}}-\frac{0.25}{0.75}\right)^{-2}}=\frac{\beta(1-\beta)^{\frac{1-\beta}{\beta}} e_{2}^{\frac{\beta+1}{\beta}}}{\left(0.25^{\frac{2}{3}} 0.12^{\frac{1}{3}}+0.75^{\frac{2}{3}} w^{\frac{1}{3}}\right)^{\frac{3(1-\beta)}{\beta}}}, \\
\frac{\beta a b^{a}}{[\beta(a-1)-1]} \frac{(1-\beta)^{\frac{1}{\beta}}\left(\frac{0.75}{w}\right)^{\frac{2}{3}}}{\left(0.25^{\frac{2}{3}} 0.12^{\frac{1}{3}}+0.75^{\frac{2}{3}} w^{\frac{1}{3}}\right)^{\frac{3-2 \beta}{\beta}} e_{2}^{\frac{1-\beta(a-1)}{\beta}}=\left(1-\left(\frac{b}{e_{1}}\right)^{a}\right) .} .
\end{gathered}
$$

The numerical solution to this system of equations provides the calibrated values of the parameters of the model, as well as the values of the other endogenous variables: $\beta=0.36$, $a=4.775, b=3.269, w=5.52, e_{1}=4.53$ and $e_{2}=5.48$. 
TABLES

Table 1.- Actual size of occupational groups: Spanish non-agricultural market economy

\begin{tabular}{l|c|c|c|c|c}
\hline & Employees & Employers & Managers & $\begin{array}{c}\text { Solo } \\
\text { entrepreneurs }\end{array}$ & Total \\
\hline \multicolumn{7}{c}{ Year 2013 } \\
\hline $\begin{array}{l}\text { Number } \\
\text { (thousand) }\end{array}$ & 10,250 & 850 & 350 & 1,750 & 13,200 \\
\hline Percentage & $77.80 \%$ & $6.40 \%$ & $2.60 \%$ & $13.20 \%$ & $100 \%$ \\
\hline \multicolumn{7}{c}{ Year 2005 } \\
\hline $\begin{array}{l}\text { Number } \\
\text { (thousand) }\end{array}$ & 11,100 & 885 & 270 & 1,700 & 13,955 \\
\hline Percentage & $79.54 \%$ & $6.34 \%$ & $1.93 \%$ & $12.18 \%$ & $100 \%$ \\
\hline
\end{tabular}

Source: Own elaboration from INE-EPA

Table 2. Distribution of firms with employees and occupied individuals: Observed proportions and proportions predicted from the model

Percentage of firms over the total number of firms with salaried employees (1)

\begin{tabular}{l|c|c|c|c|c}
\hline Sizes (by \# employees) & $\begin{array}{c}1 \text { to } 9 \\
\text { (Micro) }\end{array}$ & $\begin{array}{c}10 \text { to } 49 \\
\text { (Small) }\end{array}$ & $\begin{array}{c}50 \text { to } 249 \\
\text { (Medium) }\end{array}$ & $\begin{array}{c}\text { More than } 249 \\
\text { (Large) }\end{array}$ & Total \\
\hline Observed data in 2013 & $90.70 \%$ & $7.77 \%$ & $1.30 \%$ & $0.26 \%$ & $100 \%$ \\
Observed data in 2005 & $87.71 \%$ & $10.48 \%$ & $1.54 \%$ & $0.27 \%$ & $100 \%$ \\
Predicted data (by the model) & $87.40 \%$ & $10.95 \%$ & $1.43 \%$ & $0.22 \%$ & $100 \%$ \\
\hline
\end{tabular}

Percentage of occupied individuals in firms with salaried employees (2)

\begin{tabular}{l|c|c|c|c|c}
\hline Sizes (by \# employees) & $\begin{array}{c}1 \text { to } 9 \\
\text { (Micro) }\end{array}$ & $\begin{array}{c}10 \text { to } 49 \\
\text { (Small) }\end{array}$ & $\begin{array}{c}50 \text { to } 249 \\
\text { (Medium) }\end{array}$ & $\begin{array}{c}\text { More than 249 } \\
\text { (Large) }\end{array}$ & Total \\
\hline Observed data in 2013 & $40.70 \%$ & $19.25 \%$ & $13.51 \%$ & $26.16 \%$ & $100 \%$ \\
Observed data in 2009 & $40.60 \%$ & $21.30 \%$ & $14.1 \%$ & $24.00 \%$ & $100 \%$ \\
Predicted data (by the model) & $40.30 \%$ & $21.30 \%$ & $13.40 \%$ & $25.00 \%$ & $100 \%$ \\
\hline
\end{tabular}

1. The number of firms with employees in 2005 and 2013 is 1.5 million.

2. The number of individuals occupied in firms with employees (employees, managers, and employed) is 12.3 million in 2009 and 11.4 million in 2013.

Source: Observed: Ministerio de Industria, Energía y Turismo (2014); OECD (2015). Predicted: simulation results with parameter values: $c=0.12, \theta=1, \mu=0.75, \rho=0.5, \beta=0.36, a=4.78, b=3.27$. 
Table 3. Comparative static analysis: Each number is the percent change in the value of the endogenous variable resulting from a one-percent change in the value of the respective parameter.

\begin{tabular}{|c|c|c|c|c|c|c|c|}
\hline & \multirow[b]{2}{*}{ Organization } & \multicolumn{2}{|c|}{ Distribution of skills } & \multirow{2}{*}{$\begin{array}{l}\text { Cost of } \\
\text { Capital }\end{array}$} & \multirow{2}{*}{$\begin{array}{l}\text { Elasticity } \\
\text { Labor }\end{array}$} & \multirow{2}{*}{$\begin{array}{c}\text { Elasticity } \\
\text { Substitution }\end{array}$} & \multirow{2}{*}{$\begin{array}{c}\text { General } \\
\text { Productivity }\end{array}$} \\
\hline & & $\begin{array}{l}\text { Lower } \\
\text { bound }\end{array}$ & $\begin{array}{c}\text { Dispersion } \\
\text { (Inverse) }\end{array}$ & & & & \\
\hline & $\beta$ & $b$ & $a$ & $c$ & $\mu$ & $\rho$ & $\theta$ \\
\hline \multicolumn{8}{|c|}{ Entrepreneurs } \\
\hline Solo & 3.13 & -2.61 & 6.97 & -0.32 & -3.92 & -0.46 & 0.32 \\
\hline Managers & 3.49 & 0.75 & 1.89 & 0.13 & 0.95 & 0.09 & -0.13 \\
\hline \multicolumn{8}{|c|}{ Output } \\
\hline Total & -0.72 & 1.39 & -1.95 & -0.06 & -0.97 & -0.13 & 1.06 \\
\hline $\begin{array}{l}\text { Per firm with } \\
\text { employees }\end{array}$ & -4.56 & 0.95 & -4.72 & -0.16 & -1.47 & -0.16 & 1.16 \\
\hline \multicolumn{8}{|c|}{ Sizes of firms } \\
\hline $\begin{array}{l}\text { Average } \\
\text { employees } \\
\text { per firm }\end{array}$ & -4.38 & -0.42 & -3.25 & -0.10 & -0.45 & -0.02 & 0.10 \\
\hline $\mathrm{L}_{\min }$ & -1.64 & -0.42 & 0.45 & -0.10 & -0.45 & -0.02 & 0.10 \\
\hline $\begin{array}{l}\text { Firms with L } \\
>50\end{array}$ & -5.12 & -0.53 & -3.55 & -0.12 & -0.56 & -0.03 & 0.12 \\
\hline $\begin{array}{l}\text { Occupied in } \\
\text { firms with } \\
L>249\end{array}$ & -5.86 & 0.21 & -7.40 & 0.01 & 0.39 & 0.06 & -0.01 \\
\hline
\end{tabular}




\section{FIGURES}
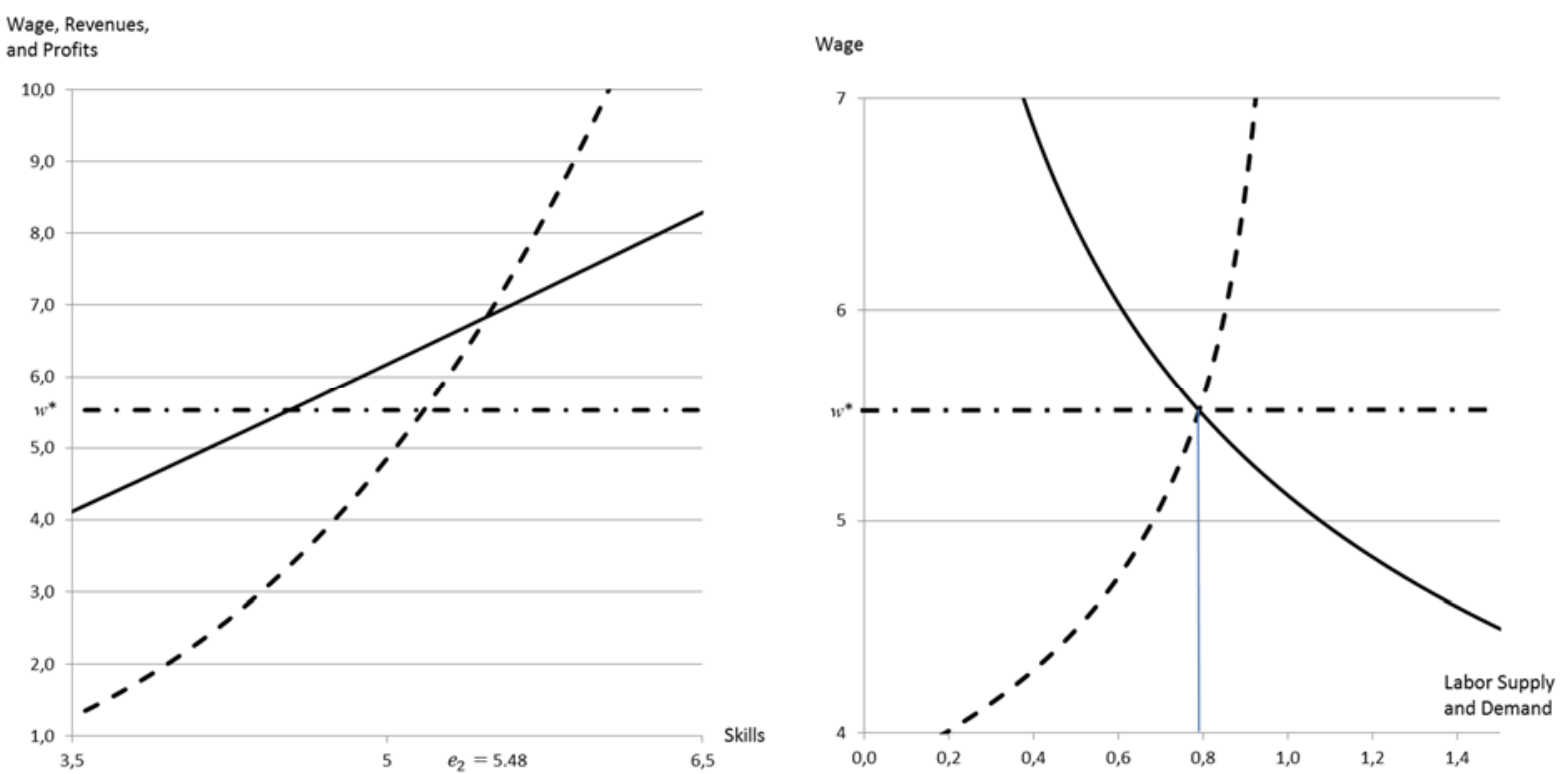

Figure 1. Market equilibrium: In the left figure, the salary of employees (dot-dashed line), the profits of employer-managers (dashed line), and income (solid line) of solo entrepreneurs as a function of the level of skills. In the right figure, the market equilibrium from the supply (dashed line) and the demand (continuous line) of/for employees as a function of market salary. The equilibrium point $\left(L^{*}, w^{*}\right)$ gives the proportion of individuals working as employees from the distribution of skills, 0.79 , and the equilibrium wage, $w^{*}=5.52$. Values of exogenous parameters: $\theta=1, c=0.12, \mu=0.75, \rho=0.5, a=4.775, b=3.269$, and $\beta=0.36$.
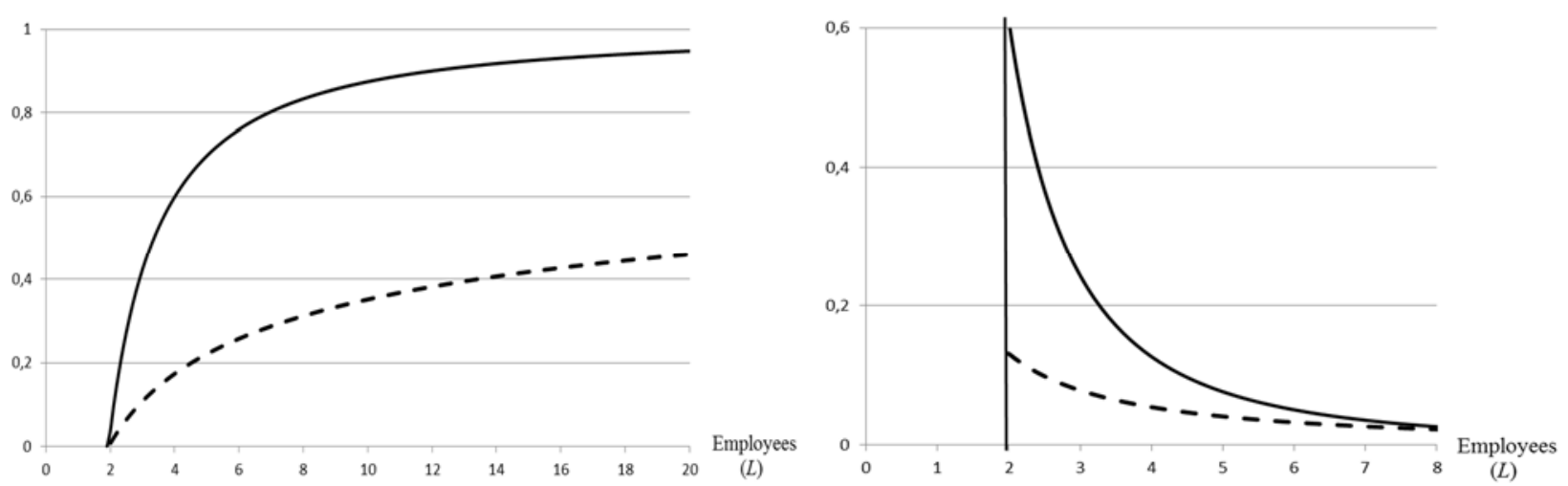

Figure 2. Cumulative (left) and density (right) functions of number of firms (continuous line) and of number of employees (dashed line), as a function of the number of employees: calibrated values of parameters as in Figure 1. 


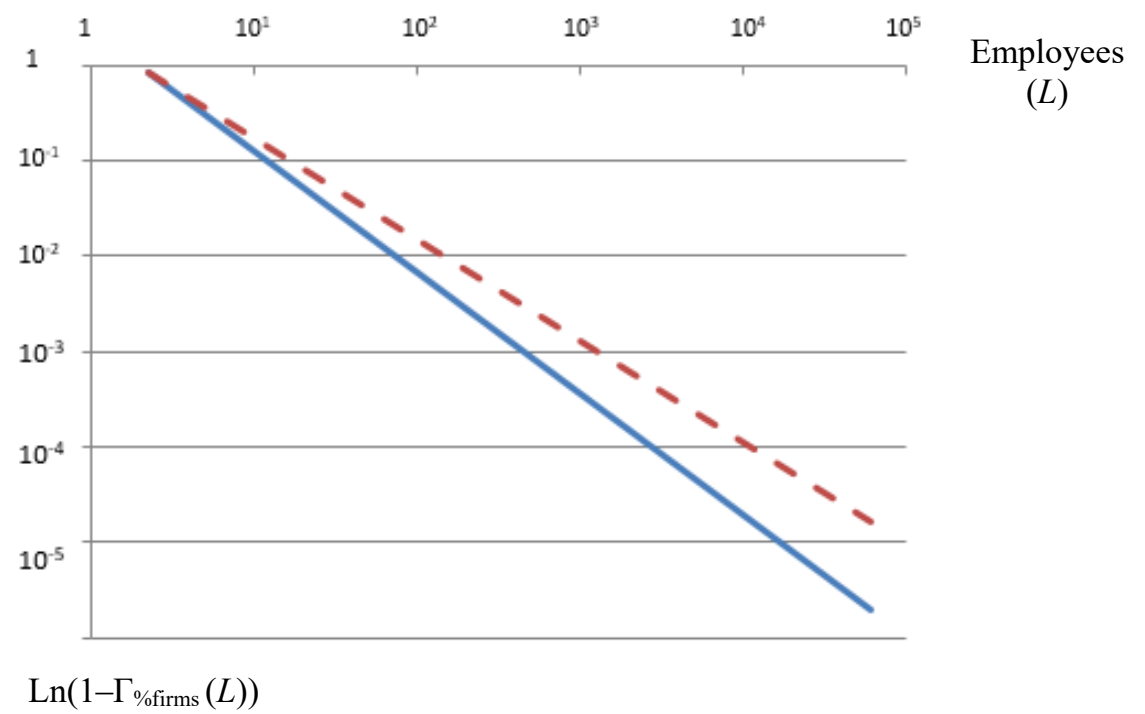

Figure 3. The Zipf - plots of the distribution of firm sizes in the Spanish economy (solid line) and in the US economy (dashed line). For each number of employees $L$, it represents the proportion of firms with $L$ or more employees, $1-\Gamma_{\% \text { firms }}(L)$, with log scales. The values of the power parameters are 1.265 for Spain and 1.059 for the US.

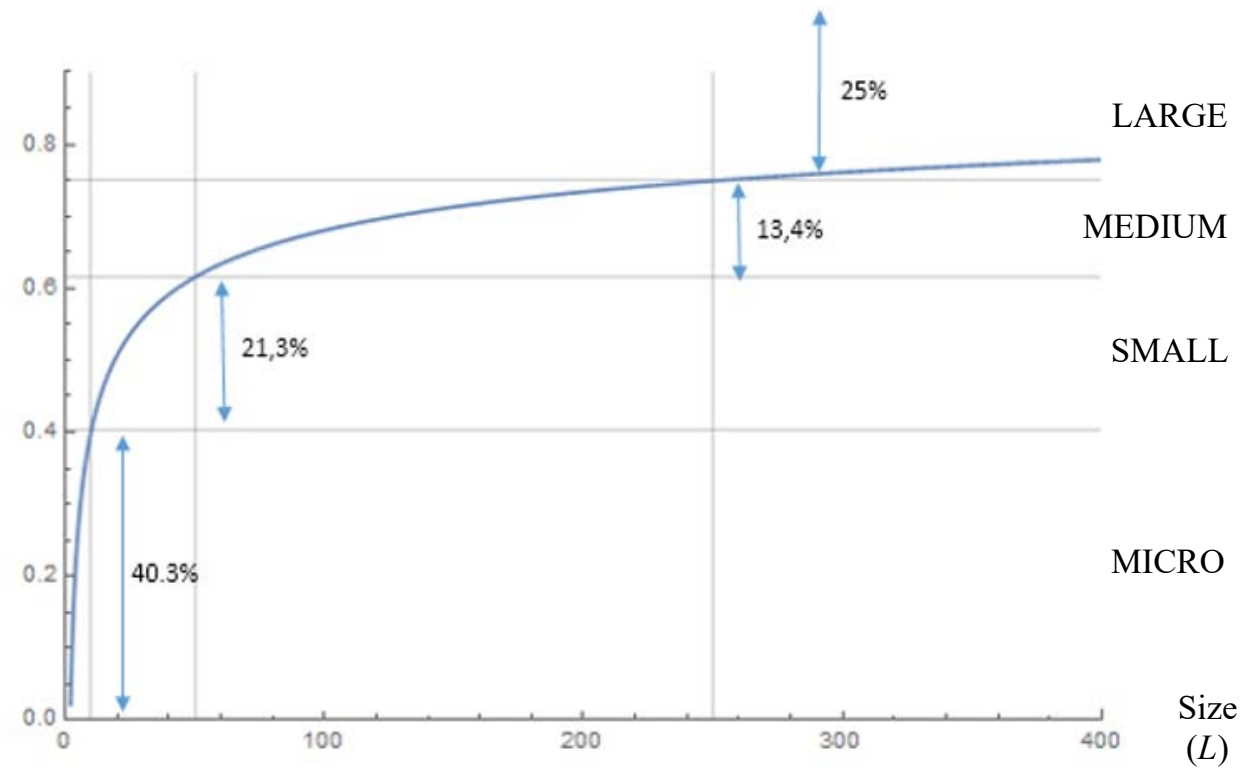

Figure 4. Distribution of occupied persons as a function of the size of the firm (number of employees) in Spain, and proportions of occupied persons in micro, small, medium, and large firms in Spain (Table 2). Calibrated values of the parameters as in Figure 1. 